Linköping Studies in Science and Technology

Dissertation No. 2003

\title{
Growth of 3C-SiC and Graphene for Solar Water-Splitting Application
}

\section{Yuchen Shi}

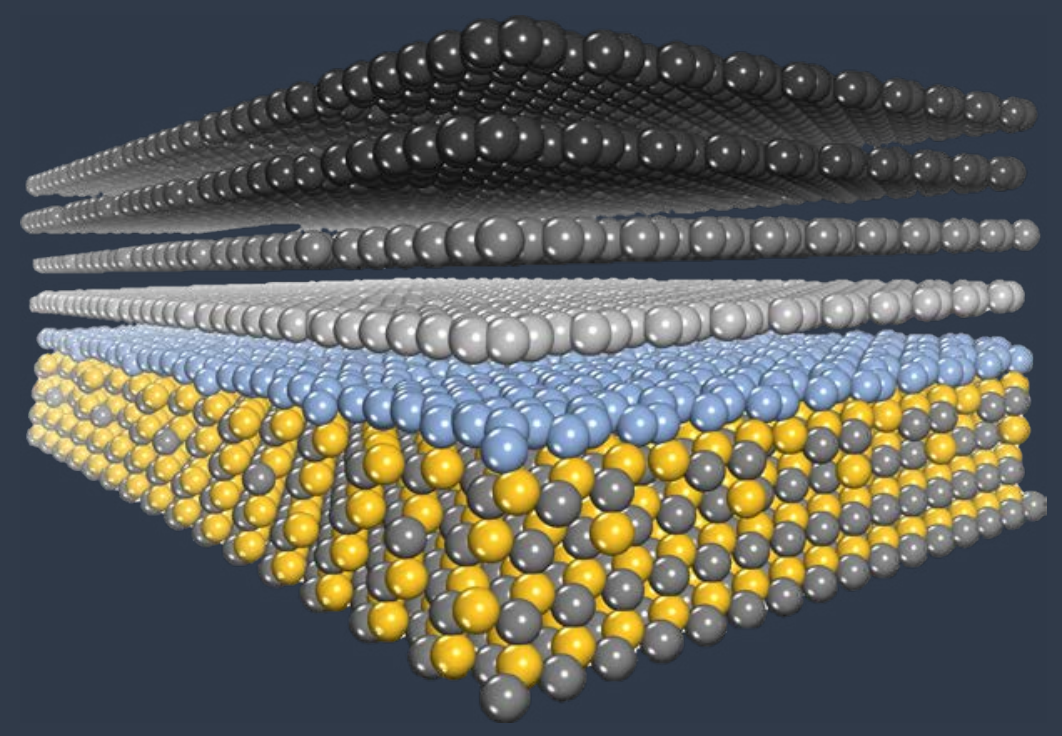


Linköping Studies in Science and Technology

Dissertation No. 2003

\title{
Growth of 3C-SiC and Graphene for Solar Water-Splitting Application
}

\author{
Yuchen Shi
}

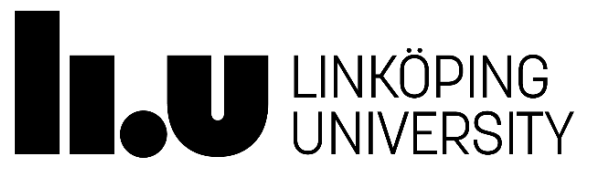

Semiconductor Materials Division

Department of Physics, Chemistry and Biology (IFM)

Linköping University

SE-581 83 Linköping, Sweden

Linköping, 2019 
(C) Yuchen Shi, 2019

Printed in Sweden by LiU-Tryck, Linköping, Sweden 2019

ISBN: 978-91-7685-021-3

ISSN 0345-7524 


\section{ABSTRACT}

Silicon carbide $(\mathrm{SiC})$ is regarded as an important semiconductor for a variety of applications including high-temperature, high-power and high-frequency devices. The most common polytypes of $\mathrm{SiC}$ are hexagonal $(4 \mathrm{H}-$ or $6 \mathrm{H}-\mathrm{SiC})$ and cubic silicon carbide (3C-SiC), which differ from each other by the ordering of the $\mathrm{Si}-\mathrm{C}$ bilayers along the c-axis crystal direction. Among different polytypes of $\mathrm{SiC}, 3 \mathrm{C}-\mathrm{SiC}$ has attracted specific interest due to its prominent properties such as high electron mobility and low interface trap density in MOSFET devices. Moreover, with a relatively small bandgap of $2.36 \mathrm{eV}$ and suitable conduction and valence band positions, $3 \mathrm{C}-\mathrm{SiC}$ has also been considered as a promising material for solar water splitting application, which provides a completely renewable approach to convert solar energy into storable hydrogen fuel. However, the growth of high-quality $3 \mathrm{C}-\mathrm{SiC}$ remains a great challenge for decades.

Graphene, a single layer of $\mathrm{sp}^{2}$-bonded carbon atoms, has shown outstanding electronic properties and becomes the most promising candidate for next-generation electronic and optoelectronic devices. Epitaxial growth of graphene on $\mathrm{SiC}$ substrates by sublimation of $\mathrm{Si}$ from $\mathrm{SiC}$ provides a feasible route to fabricate wafer-scale device-quality graphene. The most advantage of this method is that a variety of devices can be processed directly on graphene/SiC without any transfer process, which is needed in the case of graphene produced by exfoliation or CVD on metals. During past years, the growth of monolayer (ML) graphene on hexagonal $\mathrm{SiC}(6 \mathrm{H}-\mathrm{SiC}, 4 \mathrm{H}-\mathrm{SiC})$ substrates has been extensively studied. However, it is challenging to grow large-area and uniform multilayer graphene on hexagonal $\mathrm{SiC}$ substrates due to the stepbunching issue during the sublimation growth.

Multilayer graphene has recently attracted great interest due to its tunable electronic properties for various electronic and optoelectronic applications. It has been shown that the electronic properties of multilayer graphene are strongly influenced by its stacking sequence. In particular, the rhombohedral stacking sequence (ABC stacking) has shown its potential to introduce a flat band energy dispersion at the K points of the Brillouin zone, which would result in many exotic phases of matter such as superconductivity. Among various $\mathrm{SiC}$ polytypes, $3 \mathrm{C}$ $\mathrm{SiC}$ is predicted to be the most suitable substrate for the epitaxial growth of rhombohedral multilayer graphene.

This thesis work mainly covers the sublimation growth of high-quality Si-face and C-face $3 \mathrm{C}$-SiC on off-oriented $4 \mathrm{H}-\mathrm{SiC}$, exploring the proper parameter window for the growth of 
homogeneous graphene layers ranging from monolayer to multilayer on $\mathrm{Si}$-face off-oriented $3 \mathrm{C}$-SiC and the growth of graphene on $\mathrm{C}$-face $3 \mathrm{C}$-SiC, as well as the characterizations on $3 \mathrm{C}$ $\mathrm{SiC}$ and graphene. Moreover, as a proof of concept, photoelectrochemical (PEC) water splitting cells based on the Si-face and $\mathrm{C}$-face $3 \mathrm{C}$-SiC have been fabricated to study the conversion of solar energy into chemical fuel, hydrogen.

Firstly, the high-quality bulk-like Si-face and C-face 3C-SiC(111) were grown on 4degree off-oriented $4 \mathrm{H}-\mathrm{SiC}$ substrates by the sublimation epitaxy technique. The $\mathrm{C}$-face sample exhibited a smoother surface with a step height of one-unit cell without the step bunching. In contrast, the $\mathrm{Si}$-face $3 \mathrm{C}$-SiC showed larger steps with a height of two-unit cells of $3 \mathrm{C}-\mathrm{SiC}$ due to the pronounced step bunching. The cross-sectional studies showed that $\mathrm{C}$-face 3C-SiC exhibited less polytype-transition layer than the Si-face sample. This would help the lateral enlargement of 3C-SiC domains. We also demonstrated that the crystalline quality of $\mathrm{C}$-face 3C-SiC was comparable to the Si-face sample.

Secondly, we systematically studied the growth of monolayer and multilayer graphene on off-axis 3C-SiC(111). Taking advantage of the synergistic effect of periodic $\mathrm{SiC}$ step edges as graphene nucleation sites and the unique thermal decomposition energy of 3C-SiC steps, we demonstrated that the step bunching was fully eliminated during graphene growth on Si-face 3C-SiC and large-area monolayer, bilayer, and four-layer graphene were controllably obtained on high-quality off-axis Si-face 3C-SiC(111). The growth of uniform four-layer graphene over areas of tens of square micrometers was demonstrated. The electronic structures of multilayer graphene with different stacking sequences were systematically studied by experimental and theoretical analysis. It was demonstrated that the four-layer graphene exhibited rhombohedral stacking sequence, which introduced a flat band near the Fermi level. Moreover, the flat-band width and bandgap can be tuned by the interlayer spacing of graphene. In contrast, graphene layers grown on the off-axis C-face $3 \mathrm{C}-\mathrm{SiC}(\overline{1} \overline{1} \overline{1})$ showed $1 \mathrm{ML}$ to $4 \mathrm{ML}$ graphene domains with large-area coverage over several of square micrometers and there was no buffer layer underneath. The low energy electron diffraction pattern collected on the monolayer graphene domain demonstrated four sets of graphene $(1 \times 1)$ spots, indicating the existence of rotational disorders within the monolayer graphene. To compare with graphene growth on the off-oriented $3 \mathrm{C}-\mathrm{SiC}$, the growth of graphene on off-oriented $4 \mathrm{H}-\mathrm{SiC}$ epilayers was also explored. $\mathrm{The} 4 \mathrm{H}-$ $\mathrm{SiC}$ epilayers were first grown on 4-degree off-oriented $4 \mathrm{H}-\mathrm{SiC}$ substrates and periodically inclined step facets in-between terraces were induced on $4 \mathrm{H}-\mathrm{SiC}$ epilayers due to the pronounced step bunching. The graphene grown on such step-structured surface of off-oriented 
4H-SiC showed that the terraces were mainly covered by monolayer graphene and the buffer layer underneath it while on the step facets, graphene was strongly buckled and appeared to be largely decoupled from the surface.

Finally, the PEC water splitting performance based on the Si-face and C-face 3C-SiC was systematically studied. It was found that the $\mathrm{SiC}$ surface polarity played an important role in the PEC performance. The influence of both Si-face and C-face on surface proton transfer was investigated. It was demonstrated that the $\mathrm{Si}$-face $\mathrm{SiC}$ was more energy-favorable, thus making oxygen evolution reaction operate at a very low overpotential. Furthermore, the PEC watersplitting performance was significantly enhanced by using $\mathrm{NiO} / 3 \mathrm{C}-\mathrm{SiC}$ p-n junction as a photoanode. A high photovoltage of $1.0 \mathrm{~V}$, a photocurrent density of $1.01 \mathrm{~mA} / \mathrm{cm}^{-2}$ at $0.55 \mathrm{~V}$ versus reversible hydrogen electrode $\left(\mathrm{V}_{\mathrm{RHE}}\right)$, a low onset potential of $0.20 \mathrm{~V}_{\mathrm{RHE}}$ and a high fill factor of $57 \%$ were demonstrated in the PEC water splitting cell under AM1.5G $100 \mathrm{~mW} \mathrm{~cm} \mathrm{~cm}^{-2}$ illumination. 


\section{POPULÄRVETENSKAPLIG SAMMANFATTNING}

Kiselkarbid ( $\mathrm{SiC}$ ) anses som en viktig halvledare för en rad olika tillämpningar som inkluderar användning vid hög temperatur, hög effekt och höga frekvenser. De vanligaste polytyperna av kiselkarbid är hexagonal (4H- eller 6H-SiC) och kubisk kiselkarbid (3C-SiC), de skiljer sig från varandra genom hur bilager av Si och $\mathrm{C}$ ordnas i kristallriktningen längs med c-axeln. Bland de olika polytyperna har 3C-SiC lockat specifikt intresse genom sina attraktiva egenskaper som hög elektronmobilitet och låg densitet av gränssnittsfällor i MOSFET-komponenter. Vidare gör det relativt låga bandgapet på $2.36 \mathrm{eV}$ och lämpliga positioner av valens- och ledningsband att 3C-SiC även anses som ett lovande material för soltillämpningar inom vattendelning, vilket medger ett helt förnybart sätt att omvandla solenergi till lagringsbar vätgasbränsle. Emellertid kvarstår tillväxt av högkvalitativ 3C-SiC som en utmaning sedan årtionden.

Grafen, ett enkelt lager av sp2-bundna kolatomer, uppvisat enastående elektroniska egenskaper och blivit den mest lovande kandidaten för nästa generation elektroniska och optoelektroniska komponenter. Epitaxiell tillväxt av grafen på kiselkarbidsubstrat genom sublimation av kisel från kiselkarbid ger en görlig väg för att producera komponentkvalitet av grafen i waferstorlek. Den främsta fördelen av denna metod är att flera typer av komponenter kan processas direkt på grafen/SiC utan en överföringsprocess, vilket är behövligt för grafen framställd genom exfoliering eller CVD på metaller. Under de senaste åren har omfattande studier gjorts kring framställning av monolager (ML) av grafen på hexagonala substrat av SiC (6H-SiC, 4H-SiC). Dock så är det utmanande att växa multilager av grafen på hexagonal kiselkarbid uniformt över stor yta på grund av anhopning av steg under sublimationstillväxten.

Multilager-grafen har nyligen lockat stort intresse på grund av möjligheten att justera elektroniska egenskaper för olika elektroniska och optoelektroniska tillämpningar. Det är visat att de elektroniska egenskaperna av multilager av grafen påverkas starkt av stackningssekvensen. Särskilt har den romboedriska stackningssekvensen (ABC stackning) uppvisat sin potential att introducera flatbandsenergidispersion vid K-punkter i Brillouinzonen, vilket skulle resultera i flertal exotiska materialfaser som exempelvis supraledning. Av de olika kiselkarbidpolytyperna är 3C-SiC förutspådd att vara det mest lämpliga substratet för epitaxiell tillväxt av romboedrisk multilager av grafen.

Avhandlingens arbete täcker främst sublimationstillväxt av högkvalitativ kisel- och kolyta av 3C-SiC på vinklad yta av 4H-SiC, undersöker lämpligt fönster av parametrar för tillväxt av homogena grafenlager, som sträcker sig från monolager till multilager, på kiselsidan 
av 3C-SiC med vinklade ytor, och tillväxt av grafen på kolsidan av 3C-SiC, som såväl karakterisering av 3C-SiC och grafen. Vidare, som bevisning av koncept, har fotoelektrokemiska (PEC) vattendelningsceller baserat på kisel-och kolsidan av 3C-SiC tillverkats för att studera konversion av solenergi till kemiskt bränsle (vätgas).

För det första har högkvalitativ bulkliknande kisel- och kolsida av 3C-SiC(111) framställts på 4 graders vinklad yta av $4 \mathrm{H}-\mathrm{SiC}$ substrat genom sublimationsepitaxiteknik. Prover med kolsida uppvisade en mer slät yta med en steghöjd av en enhetscell utan steganhopning. Jämförelsevis uppvisade kiselsidan av 3C-SiC större steg med en höjd av två enhetsceller av 3C-SiC på grund av den mer markanta steganhopningen. Genomskärningsstudier visade att kolsida av 3C-SiC hade snävare polytypövergång än kiselsidan. Detta skulle kunna bidra till lateral expansion av 3C-SiC domäner. Vi har även demonstrerat att den kristallina kvaliteten av materialbitar med kolsida 3C-SiC var jämförbar med den för kiselsida.

För det andra studerade vi systematiskt tillväxt av monolager och multilager av grafen på vinklade ytor av 3C-SiC (111). Genom att nyttja fördelen av den synergistiska effekten av periodiska stegkanter i kiselkarbid och den unika termiska dekompositionsenergin för steg i 3C-SiC har vi demonstrerat att anhopning av steg blev helt eliminerad under grafentillväxt på kiselsidan av 3C-SiC och monolager, bilager och fyralager av grafen erhölls på ett kontrollerat sätt på högkvalitativ vinklad yta på kiselsida av 3C-SiC(111). Tillväxt av uniform fyralagersgrafen över area på tiotals kvadratmillimeter har uppvisats. Den elektroniska strukturen av multilager-grafen beroende på stackningssekvensen studerades systematiskt genom experimentell och teoretisk analys. Arbetet demonstrerade att fyralager av grafen uppvisade romboedrisk stackningssekvens, vilket introducerade ett flatband nära Ferminivån. Dessutom kan bandgapet och flatbandets bredd ställas in genom att variera mellanrummet av gränslager i grafen. Som kontrast visar grafen framställd på kolsidan av vinklad yta av $3 \mathrm{C}-\mathrm{SiC}(\overline{1} \overline{1} \overline{1})$ en till fyra ML av grafendomäner som täckte stora ytor över flera kvadratmikrometer och det fanns inget bufferlager under. Diffraktionsmönstret av lågenergielektroner på enlager av grafendomäner visade fyra uppsättningar av $(1 \times 1)$ punkter, vilket indikerar existens av roterande oordning innanför monolagergrafen. Vidare undersöktes tillväxt av grafen på ytvinklad $4 \mathrm{H}-\mathrm{SiC}$ epilager för jämförelse med 3C-SiC. $4 \mathrm{H}-\mathrm{SiC}$ epilager framställdes på 4 graders $4 \mathrm{H}-\mathrm{SiC}$ substrat och inducerade periodiska sluttande facetter av steg mellan terasser på grund av makrosteganhopning. Grafen framställd på sådana stegstrukturer av ytvinklad 4H-SiC 
visade att terasserna främst täcktes av monolager av grafen och dess bufferlager, medan grafen på facetterna var starkt bucklig och till synes frikopplad från kiselkarbidytan.

Slutligen studerades systematiskt PEC vattendelningsprestandan baserat på kisel- och kolsidan av 3C-SiC. Arbetet upptäckte att polariteten av kiselkarbidytan spelar en stor roll för PEC prestandan. Påverkan av både kisel- och kolsidan på ytans protonövergång undersöktes. Studien visade att kiselsidan av $\mathrm{SiC}$ är mer energetisk gynnsam, och gjorde att syreutvecklingsreaktionen fungerar vid väldigt låg överpotential. Vidare ökade PEC vattendelningsprestandan signifikant genom att använda $\mathrm{NiO} / 3 \mathrm{C}-\mathrm{SiC}$ p-n övergång som fotoanod. Studien demonstrerade en hög fotospänning på $1.0 \mathrm{~V}$, en fotoströmdensitet på 1.01 $\mathrm{mA} / \mathrm{cm}^{-2}$ vid $0.55 \mathrm{~V}$ mot reversibel väte-elektrod ( $\left.\mathrm{V}_{\mathrm{RHE}}\right)$, en låg startpotential av $0.20 \mathrm{~V}_{\mathrm{RHE}}$ och en hög fyllnadsfaktor på 57\% i PEC vattendelningscellen under AM1.5G $100 \mathrm{~mW} \mathrm{~cm}$ c $^{-2}$ belysning. 
The studies were carried out in the Semiconductor Materials Division at the Department of Physics, Chemistry, and Biology (IFM) in Linköping University (LiU) from September 2015 to September 2019. This thesis contains two parts: the first part gives a brief introduction to the research field and the second part provides the main results summarized in seven articles.

The main aim of this thesis was to grow high crystalline quality Si-face and C-face 3C$\mathrm{SiC}$ on off-axis $4 \mathrm{H}-\mathrm{SiC}$ substrates, to explore the growth of homogeneous graphene layers on both faces of off-axis $3 \mathrm{C}-\mathrm{SiC}$ and study the electronic properties of graphene layers. The work also covers the investigation on solar water splitting performance of the $\mathrm{Si}$-face and $\mathrm{C}$-face $3 \mathrm{C}$ $\mathrm{SiC}$ and the performance based on the catalyst/3C-SiC photoanode.

This thesis work was mainly supported by The Swedish Research Council (Vetenskapsrådet, Grant No. 621-2014-5461; 2018-04670), The Swedish Research Council for Environment, Agricultural Sciences and Spatial Planning (FORMAS, Grant No. 201600559), The Swedish Foundation for International Cooperation in Research and Higher Education (STINT, Grant No. CH2016-6722), The ÅForsk foundation (Grant No. 16-399), and The Stiftelsen Olle Engkvist Byggmästare (Grant No. 189-0243). 


\section{PUBLICATIONS INCLUDED IN THE THESIS}

\section{Paper I}

Yuchen Shi, Valdas Jokubavicius, Pontus Höjer, Ivan G. Ivanov, G. Reza Yazdi, Rositsa Yakimova, Mikael Syväjärvi and Jianwu Sun

"A Comparative Study of High-quality C-face and Si-face 3C-SiC(111) grown on off-oriented 4H-SiC Substrates”

Journal of Physics D: Applied Physics, 52, 345103, 2019.

\section{Paper II}

Yuchen Shi, Alexei A. Zakharov, Ivan G. Ivanov, G. Reza Yazdi, Valdas Jokubavicius,

Mikael Syväjärvi, Rositsa Yakimova and Jianwu Sun

"Elimination of step bunching in the growth of large-area monolayer and multilayer graphene on off-axis $3 C$-SiC (111)"

Carbon 140, 533-542, 2018.

\section{Paper III}

Yuchen Shi, Alexei A. Zakharov, Ivan G. Ivanov, G. Reza Yazdi, Rositsa Yakimova, Mikael Syväjärvi and Jianwu Sun

"Epitaxial graphene growth on the step-structured surface of off-axis C-face $3 C$-SiC ( $\overline{1} \overline{1} \overline{1})$ " In manuscript.

\section{Paper IV}

Yuchen Shi, Alexei A. Zakharov, Ivan G. Ivanov, Nikolay A. Vinogradov, G. Reza Yazdi, Rositsa Yakimova, Mikael Syväjärvi and Jianwu Sun

"A patterning-free approach for growth of free-standing graphene nanoribbons using stepbunched facets of off-oriented $4 \mathrm{H}-\mathrm{SiC}(0001)$ epilayers"

Submitted manuscript.

\section{Paper V}

Weimin Wang, Yuchen Shi, Alexei A. Zakharov, Mikael Syväjärvi, Rositsa Yakimova, Roger I. G. Uhrberg and Jianwu Sun

"Flat-Band Electronic Structure and Interlayer Spacing Influence in Rhombohedral FourLayer Graphene”

Nano Letters, 18, 5862-5866, 2018. 


\section{Paper VI}

Hao Li, Huan Shang, Yuchen Shi, Rositsa Yakimova, Mikael Syväjärvi, Lizhi Zhang and Jianwu Sun

"Atomically manipulated proton transfer energizes water oxidation on silicon carbide photoanodes"

Journal of Material Chemistry A, 6, 24358, 2018.

\section{Paper VII}

Jingxin Jian, Yuchen Shi, Sebastian Ekeroth, Julien Keraudy, Mikael Syväjärvi, Rositsa Yakimova, Ulf Helmersson and Jianwu Sun

"A nanostructured NiO/cubic SiC p-n heterojunction photoanode for enhanced solar water splitting"

Journal of Material Chemistry A, 7, 4721, 2019.

\section{MY CONTRIBUTION TO THE PAPERS}

\section{Paper I-IV}

I have planned and performed all of sublimation growth experiments, characterized samples using optical microscopy, AFM and HRXRD, analyzed and interpreted data of Raman spectroscopy, low temperature PL, LEEM and LEED received from co-authors.

I have also written first versions of all the manuscripts and finalized them with input from all of co-authors .

\section{Paper V}

I have planned and done all epitaxial growth experiments and took part in the analysis and discussion of the results.

\section{Paper VI and VII}

I have prepared most of samples, explored conditions for making Ohmic contact on the backside of photoanode and participated in some discussions of the results. 


\section{ACKNOWLEDGEMENTS}

First of all, I would like to express my sincere gratitude to my supervisor Assoc. Prof. Jianwu Sun for giving me the opportunity to do my $\mathrm{PhD}$ at Linköping University, for his patient, unreserved, invaluable guidance and support on my graduate studies, experiments, logical thinking ability, as well as presentation and writing skills.

I am deeply grateful to my co-supervisor Prof. Rositsa Yakimova, for providing the sublimation growth facilities, for sharing your experiences, knowledge, and collaborations whenever I needed guidance and help. It is my pleasure to work with you and learn from you.

I am also grateful to my co-supervisor Assoc. Prof. Mikael Syväjärvi for providing the sublimation growth facilities, for his advance and help, for his experience on the growth of SiC.

I would like to thank my co-supervisor Dr. Gholam Reza Yazdi and my friend Dr. Valdas Jokubavicius for their help on the growth of graphene and SiC experimentally, for sharing their knowledge and experiences. Our discussions have great value for me.

I am also very grateful to Prof. Alexei A. Zakharov for his great help and discussions on LEEM and LEED measurements. His results are indispensable parts of my thesis.

I am also thankful to Assoc. Prof. Ivan Gueorguiev Ivanov for his assistance with Raman and Photoluminescence measurements, for sharing his expertise and fruitful discussions.

I would like to thank Nikolay A. Vinogradov for his great work on STM measurements and his helpful discussion.

Many thanks to Dr. Xianjie Liu and Jun Lu for their assistance with XPS and TEM measurements.

I would like to express gratitude to Prof. Roger I. G. Uhrberg's, Lizhi Zhang's and Ulf Helmersson's research group for their great collaborations.

I am very grateful to all co-authors for their contributions, collaborations and help, which were so important for me to finish the dissertation.

I am greatly thankful to all my colleagues (Hao Li, Jingxin Jian, Weimin Wang, Baoying Li......) and friends in Linköping. It was my great pleasure to meet you.

I owe great thanks to Assoc. Prof. Shujie Jiao, who is working in my alma mater. You recommended me to go abroad and do my $\mathrm{PhD}$ in Sweden. 
Many thanks to the Chinese Scholarship Council (CSC) for giving this opportunity and financial support to study abroad.

Last but not least, my deeply grateful to my family:

My parents, you spared no effort to love, understand and support me. You give me a gorgeous life in this world.

My wife Jiwen, you came into my life at my difficult time, believed me, accompanied me, and encouraged me to finish my PhD study. I would like to thank you for your love, care and support. 



\section{Contents}

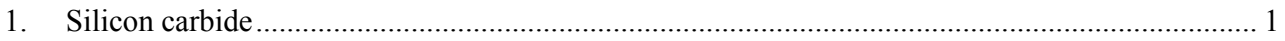

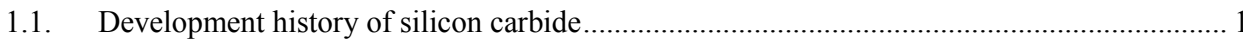

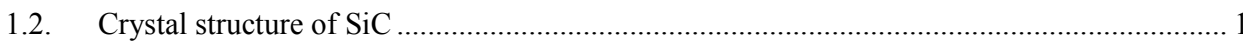

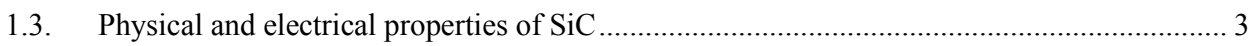

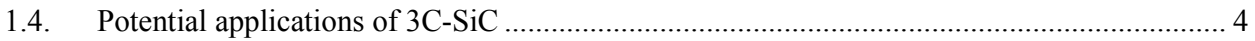

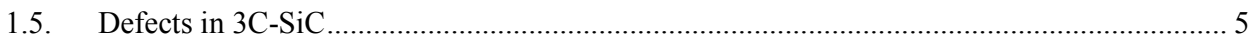

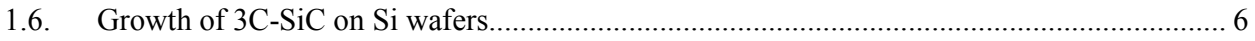

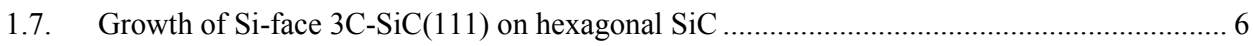

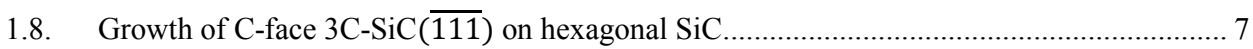

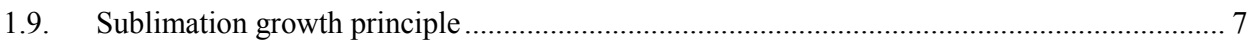

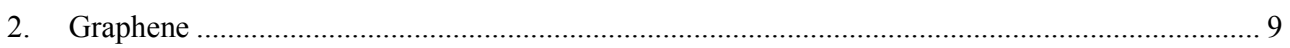

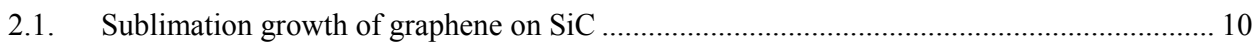

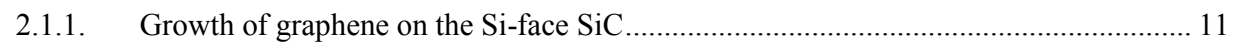

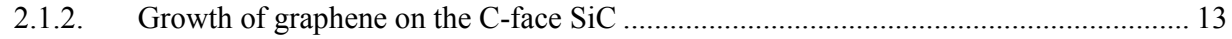

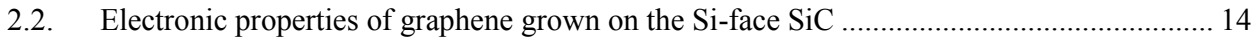

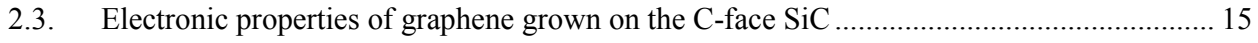

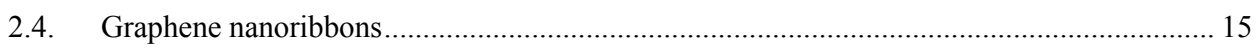

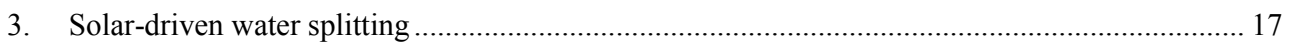

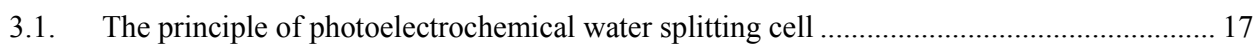

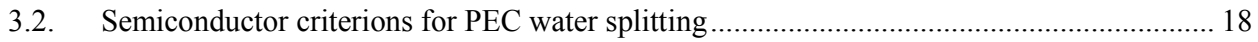

3.3. 3C-SiC as photoanode for PEC water splitting ................................................................. 20

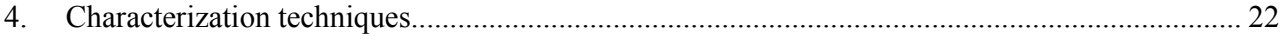

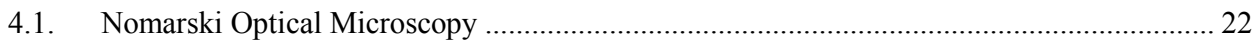

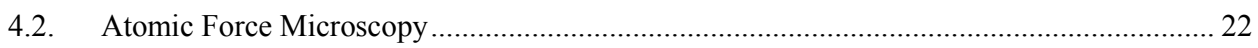

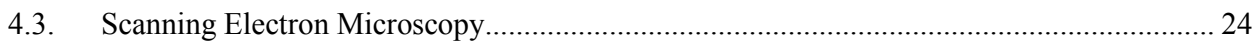

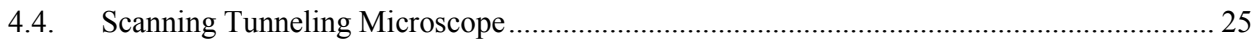

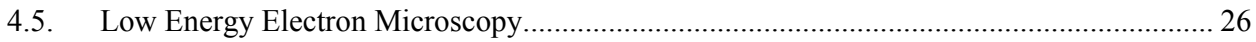

4.6. Angle-Resolved Photoemission Spectroscopy ……….......................................................... 28

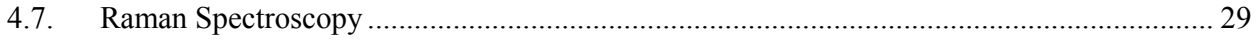

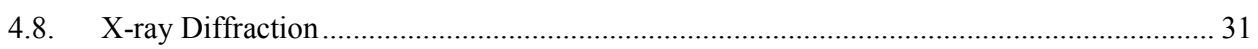

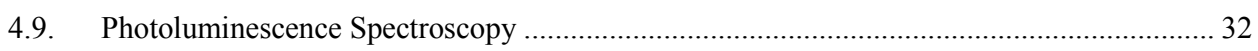

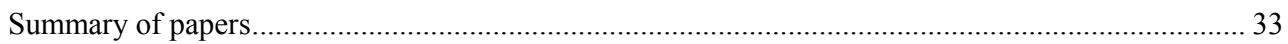

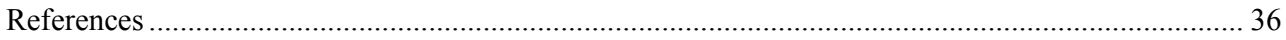





\section{Silicon carbide}

\subsection{Development history of silicon carbide}

In 1824, Jöns Jakob Berzerius first prepared silicon carbide (SiC) from the reduction process of silicon potassium fluoride. At the end of the 19th century, Paul Schuetzenberger, Henri Moissan, and Edward Goodrich Acheson studied the synthesis conditions of silicon carbide. One of the things that should be specially noted is the work of Acheson, precisely because he created an industrial method of producing silicon carbide, which led to the use of silicon carbide as a commercial artificial abrasive.

In 1893, Acheson's patent "Silicon Carbide, SIC" was published. The patent proposes an industrial method of reacting silicon dioxide and carbon with adding salt to produce silicon carbide in a carbon furnace. This method is known as the Acheson method, and this resistance furnace is called the Acheson furnace.

The earliest use of silicon carbide was in abrasives, which were subsequently used in electronic devices. In the early twentieth century, $\mathrm{SiC}$ was used as a detector in the firstgeneration radars. In 1907, Marconi’s employee, Henry Joseph Round, observed yellow, green, and orange light on the cathode by applying a certain voltage to the silicon carbide crystal, resulting in the first light-emitting diode of the world [1]. These experimental results were later confirmed by Soviet scientist Oleg Losheev in 1923. In 1955, there was a major breakthrough in theory and technology, "Lely method" proposed a concept of "sublimation of SiC powder at high temperatures and nucleation of $\mathrm{SiC}$ crystals simultaneously on the inner walls of a container", and since then SiC has been used as an important electronic material. In 1987, the silicon carbide production line was established with the research results of Cree Research Inc., and the suppliers began to provide commercial silicon carbide wafers. So far, the processing in the growth of $\mathrm{SiC}$ and the fabrication of SiC-based electronic devices has been significantly accelerated due to the commercially available $\mathrm{SiC}$ substrates.

\subsection{Crystal structure of SiC}

Silicon carbide is a wide bandgap semiconductor and compound of silicon and carbon atoms. The building block of $\mathrm{SiC}$ is a tetrahedron that can be constructed by either a silicon atom bonded to four carbon atoms or a carbon atom bonded to four Si-atoms, as shown in Fig. 1.1. The bond length between $\mathrm{Si}$ and $\mathrm{C}$ is $1.89 \AA$ and the bond length between two $\mathrm{Si}$ or $\mathrm{C}$ atoms is $3.08 \AA$. Two polar faces, which are denoted as the Si-face and $\mathrm{C}$-face, will be obtained when 
cleaving the crystal perpendicular to the c-axis. The $\mathrm{Si}-\mathrm{C}$ bonds are $88 \%$ covalent and $12 \%$ ionic. Since $\mathrm{SiC}$ has a series of polytypes with similar crystal structures, making it has the characteristics of polymorphism. There are about 250 crystal forms in silicon carbide. The crystal structure of these polymorphs can be considered as a result of laminating a plurality of specific two-dimensional structures in different stacking sequences, so that these polytypes have the same chemical composition and the same two-dimensional structure, but their threedimensional structures are different.

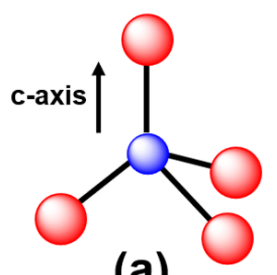

(a)

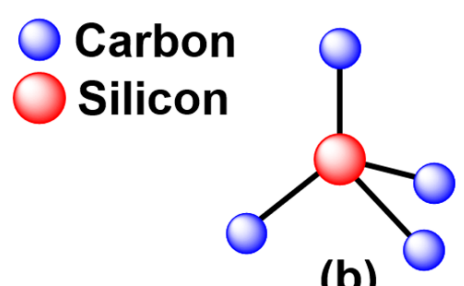

(b)

Figure 1.1. The tetrahedron building block of SiC. (a) a silicon atom bonded to four carbon atoms. (b) a carbon atom bonded to four Si-atoms.

There are three routes to stack the tetrahedrons, expressed as A, B, and C. The stacking sequences for the most commonly used $\mathrm{SiC}$ polytypes, $4 \mathrm{H}-, 6 \mathrm{H}-$ and $3 \mathrm{C}-\mathrm{SiC}$ are shown in Fig. 1.2. The stacking sequence is $\mathrm{ABCB}$ and $\mathrm{ABCACB}$ for $4 \mathrm{H}$ and $6 \mathrm{H}-\mathrm{SiC}$, respectively. For $3 \mathrm{C}$ $\mathrm{SiC}$, the stacking sequence is a repeat of $\mathrm{ABC}$.
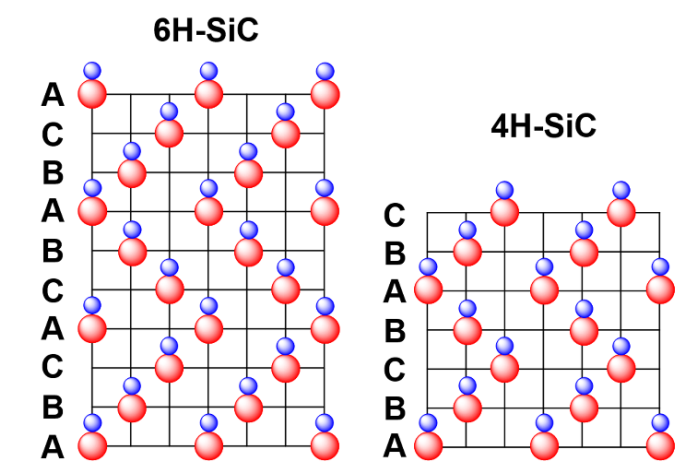

\section{- Carbon \\ Silicon}

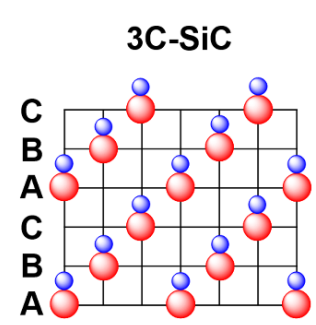

Figure 1.2. The stacking sequence of three most commonly used SiC polytypes

Different SiC polytypes possess various material properties, as displayed in Table 1. For example, $6 \mathrm{H}-$ and $4 \mathrm{H}-\mathrm{SiC}$ stacked in hexagonal structure have a wider bandgap of 3.05 and 
$3.23 \mathrm{eV}$, respectively, compared to the cubic structure with a bandgap of $2.36 \mathrm{eV}$. Different $\mathrm{SiC}$ polytypes can be used in different research fields and practical applications due to various bandgaps and other material properties.

Table 1. Material properties of three most commonly used $\mathrm{SiC}$ polytypes [2, 3].

\begin{tabular}{cccc}
\hline polytype & $6 \mathrm{H}-\mathrm{SiC}$ & $4 \mathrm{H}-\mathrm{SiC}$ & $3 \mathrm{C}-\mathrm{SiC}$ \\
\hline Crystal structure & Hexagonal & Hexagonal & Cubic \\
Bandgap $(\mathrm{eV})$ & 3.05 & 3.23 & 2.36 \\
$\begin{array}{c}\text { Lattice constant } \\
(\AA)\end{array}$ & $\begin{array}{c}\mathrm{a}=3.081 \\
\mathrm{c}=15.12\end{array}$ & $\begin{array}{c}\mathrm{a}=3.073 \\
\mathrm{c}=10.053\end{array}$ \\
\begin{tabular}{c} 
Density $(\mathrm{g} / \mathrm{cm} 3)$ \\
\hline
\end{tabular} & 3.21 & 3.21 & 3.3596 \\
\hline
\end{tabular}

\subsection{Physical and electrical properties of SiC}

SiC has many superior physical properties. Using contemporary method, high-quality SiC-based ceramics have been developed in industrial-grade. These ceramics have outstanding properties including high strength, high hardness, large elasticity modulus, large thermal shock resistance, superior thermal conductivity, good chemical inertness, small thermal expansion, and so on. These high-strength, long-lasting ceramics are used in a wide range of applications, e.g. automotive brakes and clutches, as well as ceramic panels embedded in bulletproof vests.

Table 2. Electrical properties of SiC polytypes and other widely used semiconductors [3-6].

\begin{tabular}{ccccccc}
\hline Semiconductors & $\mathrm{Si}$ & $\mathrm{GaAs}$ & $\mathrm{GaN}$ & $6 \mathrm{H}-\mathrm{SiC}$ & $4 \mathrm{H}-\mathrm{SiC}$ & $3 \mathrm{C}-\mathrm{SiC}$ \\
\hline $\begin{array}{c}\text { Thermal } \\
\text { conductivity } \\
\left(\mathrm{W} \cdot \mathrm{cm}^{-1} \cdot \mathrm{K}^{-1}\right)\end{array}$ & $1.3-1.5$ & 0.46 & 1.3 & $3.0-5.0$ & $3.0-5.0$ & $3.0-5.0$ \\
$\begin{array}{c}\text { Breakdown electric } \\
\text { field }\left(\mathrm{MV} \cdot \mathrm{cm}^{-1}\right)\end{array}$ & 0.3 & 0.4 & 3.3 & 3.05 & 3.23 & 2.36 \\
$\begin{array}{c}\text { Electron mobility } \\
\left(\mathrm{cm}^{2} \cdot \mathrm{V}^{-1} \cdot \mathrm{s}^{-1}\right)\end{array}$ & 1350 & 8500 & 900 & 600 & 460 & 1000 \\
$\begin{array}{c}\mathrm{Hole} \mathrm{mobility} \\
\left(\mathrm{cm}^{2} \cdot \mathrm{V}^{-1} \cdot \mathrm{s}^{-1}\right)\end{array}$ & 450 & 330 & 200 & 95 & 120 & 320 \\
$\begin{array}{c}\text { Electron saturated } \\
\text { drift velocity } \\
\left(10^{7} \cdot \mathrm{cm}^{-1}\right)\end{array}$ & 1.0 & 2.0 & 1.5 & 2.0 & 2.2 & 2.7 \\
\hline
\end{tabular}

$\mathrm{SiC}$ also has outstanding electrical properties among a variety of semiconductor materials, a comparison is displayed in Table 2. Why are power electronic components made by SiC so attractive? One reason is that $\mathrm{SiC}$ polytypes have higher breakdown electric field because of 
their wider bandgaps, resulting in their doping density is almost a hundred times higher than that of silicon-based devices at a certain blocking voltage. This allows a high blocking voltage to be achieved with a low on-resistance. Small on-resistance is critical for high-power devices because less heat is generated when the on-resistance is reduced, giving rise to a reduced system thermal load and increased overall efficiency. This makes $\mathrm{SiC}$ a suitable material for power devices Schottky diodes (also known as Schottky barrier diodes, or SBD), J-type FETs (or JFETs), and metal-oxide-semiconductor field effect transistors (MOSFETs). SiC is also utilized in semiconductor electronic devices that operate in high temperature and/or high voltage environments, such as flame igniters, resistive heating elements, and electronic components in harsh environments.

\subsection{Potential applications of $3 \mathrm{C}-\mathrm{SiC}$}

3C-SiC has the advantage for the production of metal-oxide-semiconductor-field-effecttransistors (MOSFETs). The reason is that $3 \mathrm{C}-\mathrm{SiC}$ has a narrower bandgap compared to $4 \mathrm{H}$ - or $6 \mathrm{H}-\mathrm{SiC}$. This allows that the highest density of states of $3 \mathrm{C}-\mathrm{SiC}$ is located in the conduction band and do not influence on the transport properties. Growing 3C-SiC epilayer on the C-face hexagonal $\mathrm{SiC}$ has been considered to obtain 2DEG due to its positive polarization charge on the $\mathrm{C}$-face $3 \mathrm{C}-\mathrm{SiC} / 6 \mathrm{H}-\mathrm{SiC}$ [7]. A two-dimensional electron gas (2DEG) is one of the key parts for the application of MOSFETs and high electron mobility transistors (HEMTs). Quantum confinement and coherence effect in a $2 \mathrm{DEG}$ has been achieved as well in a C-face $3 \mathrm{C} / 6 \mathrm{H}-\mathrm{SiC}$ hetero-structure [8]. This reveals the potential of the $\mathrm{C}$-face $3 \mathrm{C}$-SiC for the fabrication of MOSFETs and HEMTs.

$3 \mathrm{C}-\mathrm{SiC}$ can be also employed as the substrate for the epitaxial growth of graphene. The $\mathrm{Si}$-face $3 \mathrm{C}-\mathrm{SiC}$ is a proper substrate for the growth of large-area homogeneous graphene, particularly, multilayer graphene $[9,10]$. In addition, the electronic band structure of graphene epilayer grown on the $\mathrm{C}$-face $\mathrm{SiC}$ are very different from that on $\mathrm{Si}$-face [11-13], which considerably fascinates so much discussion. For example, graphene grown on the $\mathrm{C}$-face $4 \mathrm{H}-$ or $6 \mathrm{H}-\mathrm{SiC}$ exhibits higher mobility factors over that on the $\mathrm{Si}$-face at room temperature [14].

In recent years, $3 \mathrm{C}$-SiC has been considered as a promising material for promoting renewable energy applications such as solar-driven water splitting [15]. 3C-SiC has a proper bandgap which can absorb the large-range spectrum of visible light and meet the theoretical minimum value that can drive the water splitting. It also has good material durability and proper 
band edges that straddle water redox potentials. The details for the water-splitting application based on 3C-SiC will be discussed in Chapter 3.

$3 \mathrm{C}-\mathrm{SiC}$ could be also used for biosensors, solar cells and other semiconductor electronic and optoelectronic devices [16-18].

\subsection{Defects in $3 \mathrm{C}-\mathrm{SiC}$}

Double positioning boundaries (DPBs) are the most commonly observed defects in $3 \mathrm{C}$ $\mathrm{SiC}$ grown on hexagonal $\mathrm{SiC}$. The DPB is a fundamental problem and ascribed to the fact that $3 \mathrm{C}-\mathrm{SiC}$ has two types of stacking sequence with a $60^{\circ}$ rotational change (i.e. ABC and CBA). Since DPBs can be seen as cracks, they can strongly affect the electronic properties of the crystal and so that giving rise to the poor behavior of electronic devices due to bad contacts. DPBs have two types in the case of growing $3 \mathrm{C}-\mathrm{SiC}$ on hexagonal $\mathrm{SiC}$, which were denoted as "open" and "closed", as proposed previously [19]. The "Open" type means that the generated DPBs inside the crystal are enlarged to the surface. While the "closed" type is that the DPBs are gradually narrowed from the inside of the crystal to its surface. Therefore, from the side view of the crystal, the "open" and "closed" DPBs are present in "V" shape and inverted "V" shape, respectively. DPB is one of the main obstacles that need to be solved for obtaining highquality crystals and electronic applications.

Stacking faults (SFs) are structural defects that always form because of their low formation energies [20]. SFs can be divided into intrinsic and extrinsic generally. The intrinsic $\mathrm{SF}$ is formed when a Si-C bilayer is misaligned within the stacking sequence of an ideal SiC crystal. Such a case may occur due to the excess of vacancies or plastic glide caused by shear stress in the crystal. The extrinsic SF can be characterized by a new Si-C bilayer is inserted into an ideal stacking sequence due to excess of interstitial atoms in the crystal.

The polytype inclusion is another issue in the growth of $3 \mathrm{C}-\mathrm{SiC}$ on hexagonal $\mathrm{SiC}$. It originates from the nucleation instability of $3 \mathrm{C}-\mathrm{SiC}$. The $4 \mathrm{H}-\mathrm{SiC}$ or $6 \mathrm{H}-\mathrm{SiC}$ inclusions on the surface would impede the step-flow growth of $3 \mathrm{C}-\mathrm{SiC}$, as a result, $3 \mathrm{C}$-SiC cannot cover the whole surface to form a single-crystal domain. In addition, the boundaries between 3C-SiC and other polytype inclusions can dramatically degrade the material performance. The instability can be related to many growth parameters such as the concentration of impurities, $\mathrm{Si} / \mathrm{C}$ ratio, the off-cut angle, the polar face of the substrate, growth temperature, native defects and so on. 


\subsection{Growth of 3C-SiC on Si wafers}

Silicon wafers have been widely used for growing 3C-SiC epitaxially. However, using this method, 3C-SiC has a lower crystalline quality compared to its hexagonal counterparts. Due to $20 \%$ lattice constant mismatch and $8 \%$ thermal expansion coefficient mismatch in the $3 \mathrm{C}-\mathrm{SiC} / \mathrm{Si}$ material system, large residual stress and a large number of defects are generated in the growth of $3 \mathrm{C}-\mathrm{SiC}$ on $\mathrm{Si}$ wafers by chemical vapor deposition (CVD) method [21]. A buffer layer of $\mathrm{SiC}$ on $\mathrm{Si}$ substrates was introduced so as to improve the crystalline quality of $3 \mathrm{C}$-SiC [22]. However, the quality of $\mathrm{SiC}$ on $\mathrm{Si}$ wafers is still far away from the production of commercial devices [23]. Using SiC hexagonal polytypes as the substrate for the growth of 3C$\mathrm{SiC}$ is an efficient way to solve the mismatch problem. The in-plane lattice mismatch between $3 \mathrm{C}-\mathrm{SiC}$ and its hexagonal counterparts is below $0.1 \%$ and they have similar thermal expansion coefficient and chemical compatibility as well.

\subsection{Growth of Si-face 3C-SiC(111) on hexagonal SiC}

Nominally on-axis hexagonal $\mathrm{SiC}$ was commonly used as substrates for the growth of 3C-SiC epilayers via two-dimensional nucleation [24, 25]. Nevertheless, it is particularly difficult to control the nucleation of $3 \mathrm{C}-\mathrm{SiC}$ domains in this case and the reproducibility of high crystalline quality single-domain $3 \mathrm{C}-\mathrm{SiC}$ is very poor.

In order to obtain $3 \mathrm{C}-\mathrm{SiC}$ over a larger domain, using off-axis hexagonal $\mathrm{SiC}$ substrate is another choice and achievable under certain growth conditions by sublimation [26]. Most recently, it has been verified that a high-quality $3 \mathrm{C}-\mathrm{SiC}$ can be grown on off-oriented $4 \mathrm{H}-\mathrm{SiC}$ substrates through a growth mechanism of lateral enlargement in the sublimation system [27]. Particularly, even a single domain 3C-SiC could be obtained using this method [19].

In this thesis work, we grew both $\mathrm{Si}$-face and $\mathrm{C}$-face $3 \mathrm{C}$-SiC on the 4-degree off-axis $\mathrm{Si}$ face and $\mathrm{C}$-face $4 \mathrm{H}-\mathrm{SiC}$ substrates. In particular, large-area single domain C-face 3C-SiC crystals were grown by the sublimation technique. Furthermore, the growth of graphene on both Si-face and $\mathrm{C}$-face off-oriented 3C-SiC was systematically studied (Paper 1). We also demonstrate that these materials have promising properties for the application of hydrogen generation from solar-driven water splitting (Paper 6). 


\subsection{Growth of C-face $3 \mathrm{C}-\mathrm{SiC}(\overline{\mathbf{1}} \overline{\mathbf{1}} \overline{\mathbf{1}})$ on hexagonal SiC}

So far, since a lack of systematic studies, the production of C-face $3 \mathrm{C}$-SiC crystals is still fairly poor and challenging, enables us to grow C-face 3C-SiC imperatively. However, it is quite difficult to control 3C-SiC formation on $\mathrm{C}$-face hexagonal substrates.

Different methods including CVD, vapor-liquid-solid (VLS), and sublimation have been used for the growth of $\mathrm{C}$-face $3 \mathrm{C}$-SiC as well. An early stage of $3 \mathrm{C}$-SiC nucleation and islands enlargement on a C-face $6 \mathrm{H}-\mathrm{SiC}$ substrate was studied using VLS method, but the surface contains a large density of DPBs due to a high density of 3C-SiC nucleation sites [28]. Many studies have tried to suppress DPBs by optimizing some factors such as the concentration of source-gas, C/Si ratio, temperature, and surface etching [29, 30]. However, their achievements were not remarkable. Alternatively, sublimation is a promising method that can provide a proper condition at high temperature to govern the growth of $3 \mathrm{C}-\mathrm{SiC}$. The DPBs present as well in the case of growing $3 \mathrm{C}-\mathrm{SiC}$ on on-axis $\mathrm{Si}$-face substrates via sublimation technique [24]. Since we have obtained relatively high-quality and single domain $3 \mathrm{C}$-SiC grown on the Si-face $4{ }^{\circ}$ off-oriented $4 \mathrm{H}-\mathrm{SiC}(0001)$, in this thesis work, we used the same growth method and configuration to explore the growth of $3 \mathrm{C}$-SiC on the $\mathrm{C}$-face $4{ }^{\circ}$ off-oriented $4 \mathrm{H}-\mathrm{SiC}(000 \overline{1})$.

\subsection{Sublimation growth principle}

The growth configuration in this thesis work is shown in Fig. 1.3 and has been reported in the literature [27]. A tantalum (Ta) foil is put on the ground of the graphite crucible. It can act as a carbon getter that can create a silicon-rich atmosphere, which is beneficial for the crystal growth of 3C-SiC [31]. Polycrystalline $\mathrm{SiC}$ plates are used as source material and placed onto the Ta foil. Sources are covered by a graphite spacer with an opening that is used for species transport of $\mathrm{SiC}$ vapor. The distance between the source and substrate is controlled by the thickness of the spacer. The shape and size of the opening can be changed. The required shape and size of the target crystal are determined by the ones of the opening. A 4H-SiC substrate was put on the top of the spacer with the $\mathrm{C}$-face facing down for the case of $\mathrm{C}$-face growth. For growing Si-face 3C-SiC, the Si-face of $4 \mathrm{H}-\mathrm{SiC}$ substrates is facing down. A graphite plate was put on the top of the substrate for retarding backside sublimation of the substrate. The graphite crucible was heated using an induction copper coil supported by an RF generator. The crucible was heated up to high temperature (usually around $1900^{\circ} \mathrm{C}$ ), then kept at the constant growth temperature for a few hours. After the growth, the crucible is cooled down to the room 
temperature automatically. The typical growth rate of the $3 \mathrm{C}-\mathrm{SiC}$ is about $\sim 450 \mu \mathrm{m} / \mathrm{h}$. All of the experiments were done in a vacuum $\left(10^{-5} \mathrm{mbar}\right)$.

The basic principle for the sublimation growth is that high temperature in the crucible triggers the sublimation or decomposition of $\mathrm{SiC}$ sources, the $\mathrm{SiC}$ vapor species transport from the sources to the substrate subsequently since the temperature at the sources is higher than the substrate. This temperature provides the driving force for the transport of sublimed species. The major species inside the crucible at elevated temperatures are $\mathrm{Si}, \mathrm{Si}_{2}, \mathrm{Si}_{3}, \mathrm{SiC}_{2}, \mathrm{Si}_{2} \mathrm{C}$. The sublimed species at relatively low-temperature substrate undergoes recrystallization and forms single crystal $3 \mathrm{C}-\mathrm{SiC}$.

(a)

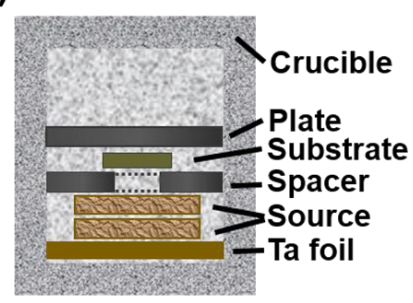

(b)

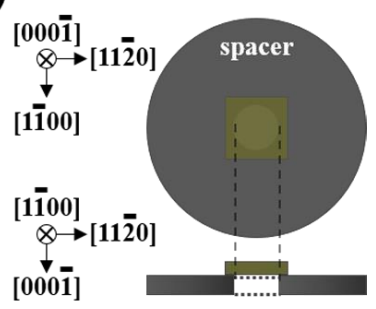

Figure 1.3. (a) Sublimation growth configuration within the crucible. (b) Placement position of the 4H$\mathrm{SiC}$ substrate on top of the spacer for the case of growth on the C-face. 


\section{Graphene}

Graphene is a two-dimensional material constructed by carbon atoms in the form of a hexagonal lattice with $\mathrm{sp}^{2}$ hybridization. There are two carbon atoms in one unit cell, as shown in Fig. 2.1(a), the distance between carbon atoms is about $0.142 \mathrm{~nm}$ and the lattice constant is about $0.246 \mathrm{~nm}$. Each carbon atom has four bonds, three $\sigma$-bonds are connected with its three neighbors and one $\pi$-bond that is perpendicular to the graphene plane. Strong $\sigma$-bond are formed by a combination of $s, p_{x}$ and $p_{y}$ orbitals in $\mathrm{sp}^{2}$ hybridization, resulting in high stability of graphene. The $\pi$-bonds are formed by unmixed $p_{z}$ orbitals and hybridize together to form noninteracting $\pi$ and $\pi^{*}$ states, where $\pi$-states form the valence band and $\pi^{*}$-states form the conduction band. These two bands meet at Dirac points in the vicinity of Fermi level, as shown in Fig 2.1(b). The Dirac points are six sites at the edges of the first Brillouin zone in momentum space and divided into two sets $\mathrm{K}$ and $\mathrm{K}$ '. These two sets are non-equivalent, and each set has three points. The bands have a linear dispersion and can be seen as two touching cones (Fig. 2.1(c, d)). Therefore, the isolated single-layer graphene is considered as a zero-bandgap semiconductor. Its linear dispersion can be written in the form of the dispersion of light: $\mathrm{E}(k)=$ $\hbar k v_{\mathrm{F}}$, where $v_{\mathrm{F}}$ is the Fermi velocity. The Fermi velocity at K point is around $1 \times 10^{6} \mathrm{~m} / \mathrm{s}$ which is closed to the speed of light so that charge carriers behave like relativistic particles, so-called massless Dirac Fermions. Therefore, the kinetic energy of electrons in graphene should conform to the relativistic expression $\mathrm{E}=\sqrt{p^{2} c^{2}+m^{2} c^{4}}$. Graphene exhibits quite high carrier mobility over $15000 \mathrm{~cm}^{2} / \mathrm{Vs}$ at room temperature [32]. That is why graphene has been expected to be used to develop a new generation of nano-electronic components or transistors. In addition, if graphene is doped, the Dirac point is located below the Fermi level for the case of n-type and above the Fermi level for the p-type (Fig. 2.1 (d)).

Besides outstanding electronic properties, graphene also possesses favorable physical properties. It is the strongest material ever tested, which exhibits an intrinsic tensile strength of $130 \mathrm{GPa}$ and Young's modulus of around 1 Tpa [33]. Among various metals, silver, copper, gold, and aluminum have relatively high thermal conductivities, while the single-layer graphene has a thermal conductivity of $5300 \mathrm{~W} / \mathrm{mK}$. Excellent thermal conductivity makes graphene the heat dissipation material for ultra-large-scale nano-integrated circuits in the future. 

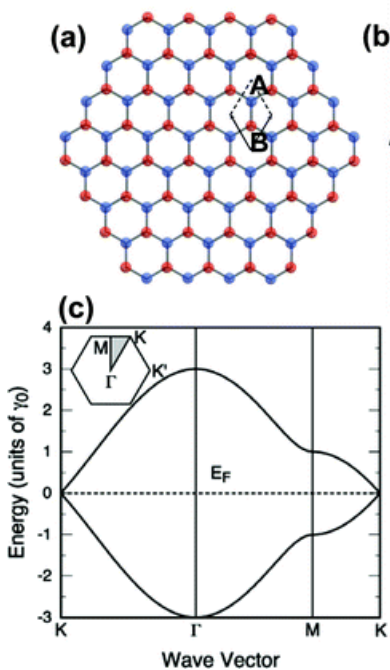

(b)

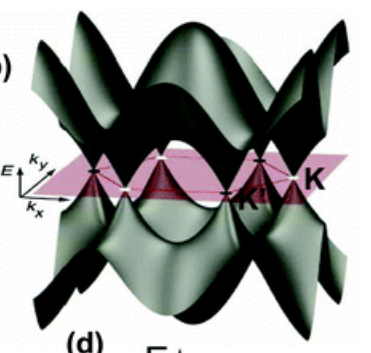

(d)

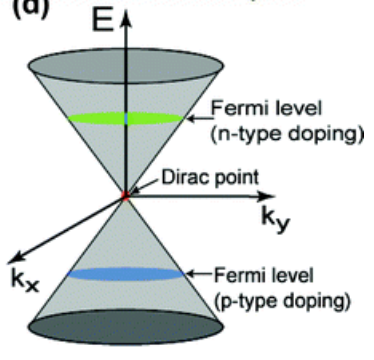

Figure 2.1. (a) Hexagonal lattice of graphene with a unit cell. (b) Calculated 3D band structure of graphene. (c) Density states of graphene. (d) Two touching cones showing the linear energy dispersion around the Dirac point. The position of the Fermi level determines the doping type. Reused from ref. [34] with permission.

Several methods containing chemical vapor deposition (CVD), highly oriented pyrolytic graphite (HOPG), chemical reduction of graphite oxide (GO) and epitaxy on bulk materials (EG) have been widely used for the graphene growth.

Epitaxial graphene on $\mathrm{SiC}$, which is a simple and effective technique, has attracted extensive research during the past decades under the background of the discovery on surface carbonization of silicon carbide [35]. The prominent superiority of this method is that graphene can be obtained directly on the semi-insulating $\mathrm{SiC}$ substrates and utilized in devices without transfer process, which is required in the cases of graphene fabricated by exfoliation or CVD on metals.

\subsection{Sublimation growth of graphene on $\mathrm{SiC}$}

The basic principle of this method is that when annealing the $\mathrm{SiC}$ substrate, silicon atoms sublime from the sample surface firstly, leaving behind carbon atoms since silicon has a high vapor pressure than carbon in the $\mathrm{SiC}$ substrate. Subsequently, a carbon-rich surface appears and undergoes reconstruction until a new graphene layer formed. Producing graphene layers using this method has started decades ago [36], although the phenomenon of surface graphitization on $\mathrm{SiC}$ had been discovered earlier [35]. 
Epitaxial graphene on $\mathrm{SiC}$ was grown in vacuum preliminarily, however, the thickness distribution of the graphene layer is quite inhomogeneous due to fast sublimation of Si atoms at high temperatures [37]. In order to suppress the sublimation rate, inert gases such as argon (Ar) and nitrogen $\left(\mathrm{N}_{2}\right)$ were employed to increase the atmospheric pressure in the growth chamber and thus the crystalline quality of graphene layer has been significantly improved [37, 38].

Graphene can be grown on both Si-face and C-face SiC, which exhibit quite different morphological, structural and electronic properties [39].

\subsubsection{Growth of graphene on the Si-face SiC}

The sublimation growth of monolayer graphene on on-axis hexagonal $\mathrm{SiC}(4 \mathrm{H}-$ and $6 \mathrm{H}-$ $\mathrm{SiC})$ substrates has been widely studied $[37,40]$. However, it is still challenging to grow largearea and uniform multilayer graphene on hexagonal $\mathrm{SiC}$ substrates due to the step-bunching process during the sublimation growth [41]. Instead, graphene is always characterized by small finger-like domains, islands or stripes [37, 42, 43].

Step-bunching is one of the main obstacles for the formation of homogeneous multilayer graphene over a large area. The step-bunching process on $4 \mathrm{H}-$ or $6 \mathrm{H}-\mathrm{SiC}$ surfaces is attributed to different thermal decomposition energies of steps. Typically, $4 \mathrm{H}-\mathrm{SiC}$ has two kinds of step energies while $6 \mathrm{H}-\mathrm{SiC}$ has three kinds of step energies, as shown in Fig. 2.2(a, b), which leads to different decomposition rates of steps during the sublimation growth. The steps with a higher decomposition rate would catch up the steps with a lower rate and form higher bunched steps with wider terraces. This would give rise to the inhomogeneous formation of a graphene layer because the graphene grown at step edges is generally thicker than that grown on terraces.

On the other hand, the nucleation sites of graphene are significantly reduced due to the presence of large bunched steps. To address this problem, the off-axis $\mathrm{SiC}$ (0001) substrates were utilized for increasing the density of steps, namely, the density of nucleation sites of graphene. However, the serious step bunching issue is generally observed when using the offaxis $\mathrm{SiC}(0001)$ as substrates [44-48]. In addition, thicker graphene layer always appears at the nanofacets of the step edge owing to faster nucleation $[38,49]$.

From this perspective, $3 \mathrm{C}$-SiC having a high density of steps is a proper substrate for the growth of multilayer graphene since it can provide a high density of nucleation sites. Moreover, it has only one step decomposition energy theoretically, as shown in Fig. 2.2(c). Thus, the steps are predicted to decompose at the same rate. It is expected to facilitate the formation of uniform 
monolayer and multilayer graphene. This is also beneficial for the formation of homogeneous multilayer graphene. It has been demonstrated that uniform monolayer graphene can be grown on $3 \mathrm{C}-\mathrm{SiC}(111)$, however, the growth of uniform multilayer graphene on off-axis $3 \mathrm{C}-\mathrm{SiC}(111)$ has not been reported yet.

In this thesis, we have systematically investigated the growth of monolayer and multilayer graphene on the Si-face off-axis 3C-SiC(111). We found that the step bunching on the Si-face of $3 \mathrm{C}-\mathrm{SiC}(111)$ can be fully eliminated during graphene growth, as a result, the large-area monolayer, bilayer, and four-layer graphene can be controllably grown via tuning the growth temperature and duration at the constant temperature (Paper 2).
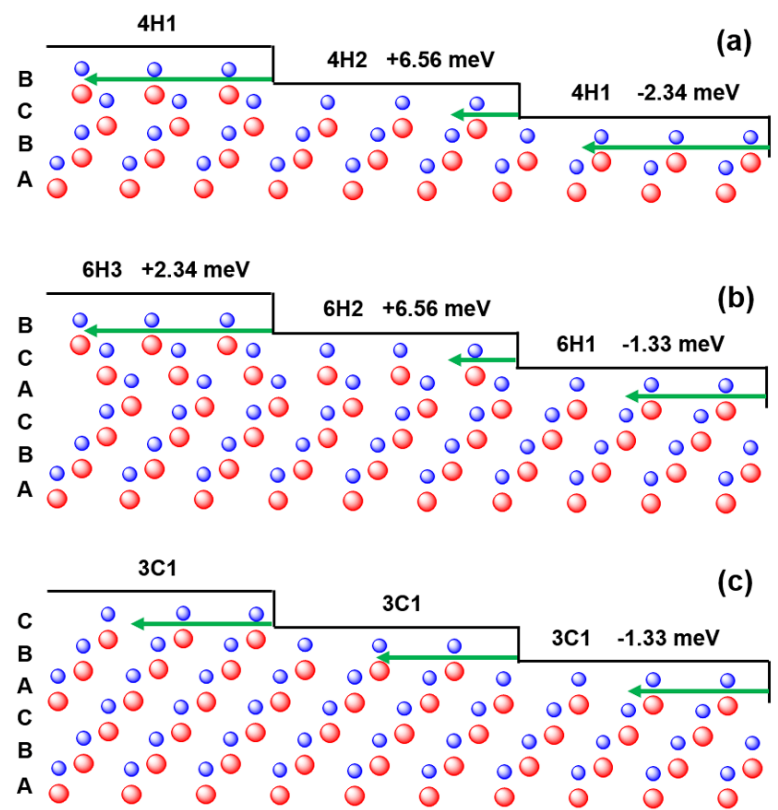

Figure 2.2. Possible terraces on $4 \mathrm{H}-\mathrm{SiC}(\mathrm{a}), 6 \mathrm{H}-\mathrm{SiC}$ (b), and 3C-SiC (c) with different decomposition energies of steps. The length of green arrows implies unequal decomposition rates of steps. Adapted from [41] with permission.

In addition, as mentioned above, the formation of a new graphene layer needs to undergo the surface re-adsorption and reconstruction of $\mathrm{C}$ atoms. The surface of $\mathrm{SiC}$ has several reconstruction structures during the growth of graphene. It has been demonstrated by LEED measurements that $(3 \times 3),(\sqrt{ } 3 \times \sqrt{ } 3),(6 \sqrt{3} \times 6 \sqrt{3}) \mathrm{R} 30^{\circ}$ reconstructions occur in sequence at elevated temperatures [50]. The $(6 \sqrt{3} \times 6 \sqrt{3}) \mathrm{R} 30^{\circ}$ reconstruction is the first formed carbon layer and so-called buffer layer (BL), of which one-third of $\mathrm{C}$ atoms are covalently bonded to 
$\mathrm{Si}$ atoms of the substrate, as shown in Fig. 2.3(a). The BL always exists between monolayer graphene (MLG) and $\mathrm{SiC}$ substrate in the case of graphene grown on the $\mathrm{Si}$-face $\mathrm{SiC}$. A typical LEED pattern of BL is shown in Fig. 2.3(b). The covalent bonding has a strong influence on the $\pi$-bands and can destroy the linearly dispersed band structure around the Dirac points [51].
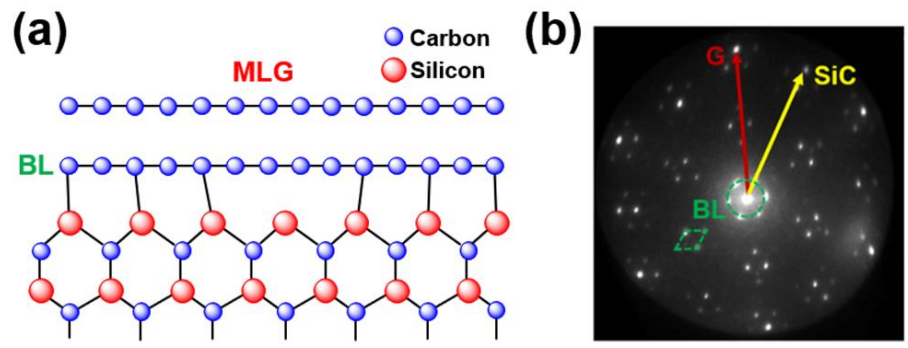

Figure 2.3. (a) Atomic structure of the buffer layer, adapted from ref. [52] with permission. (b) The $\mu$ LEED pattern measured on graphene layers showing graphene $(1 \times 1)$ spots (red arrow), $(6 \sqrt{3} \times 6 \sqrt{3})$ $\mathrm{R} 30^{\circ}$ buffer layer spots (green), as well as $\mathrm{SiC}(1 \times 1)$ spots (yellow arrow), which was collected at a start voltage of $43 \mathrm{eV}$.

\subsubsection{Growth of graphene on the $\mathrm{C}$-face $\mathrm{SiC}$}

It has been extensively found that graphene grown on the $\mathrm{C}$-face hexagonal $\mathrm{SiC}$ presents smaller domains with a larger distribution of graphene thickness than on the Si-face [39, 5357]. Unlike the Si-face, there is no evidence to manifest the existence of a buffer layer on graphene/C-face $\mathrm{SiC}$ samples so far, although $(2 \times 2),(3 \times 3)$ surface reconstructions were observed [58]. The lack of a buffer layer gives rise to a weak interaction between the first graphene layer and $\mathrm{SiC}$ substrate and thus turbostratic graphene layers including rotational stacking faults. Such rotational graphene domains/sheets can be observed by LEED patterns.

Only a few works devoted to investigating the growth of graphene on the C-face $3 \mathrm{C}$-SiC $[13,59,60]$. Studies on the morphology, surface structure and electronic band structure of graphene layers grown on the off-axis $\mathrm{C}$-face $3 \mathrm{C}$-SiC still remain unexplored.

In this work, graphene layers were grown on the off-axis C-face $3 \mathrm{C}-\mathrm{SiC}(\overline{1} \overline{1} \overline{1})$ by sublimation epitaxy. Large graphene domains enable us to measure $\mu$-LEED pattern on them. As a result, we have discovered that there is no buffer layer beneath the monolayer graphene and rotational disorders exist in the monolayer graphene (Paper 3). 


\subsection{Electronic properties of graphene grown on the Si-face SiC}

Fig. 2.4(a) shows single linear dispersed $\pi$-band of monolayer graphene grown on the $\mathrm{Si}$ face $3 \mathrm{C}-\mathrm{SiC}(111)$. The only difference of this band structure from the isolated single-layer graphene is that the Dirac point is located around $\sim 0.42 \mathrm{eV}$ below the Fermi level because of the charge transfer from the $(6 \sqrt{3} \times 6 \sqrt{3}) \mathrm{R} 30^{\circ}$ buffer layer [61]. Bilayer graphene has two hexagonal lattices in stack vertically with the atom "a" of one lattice is located exactly above the atom " $b$ " of the other. This kind of stacking is known as "Bernal" or AB stacking and supports massive Dirac fermions with quadratic dispersed $\pi$-bands. The quadratic dispersion of Bernal stacking bilayer graphene grown on the Si-face 3C-SiC(111) is shown in Fig. 2.4(b). The Dirac point is upshifted by $0.08 \mathrm{eV}$ compared to the monolayer. Bilayer graphene can be considered as a semiconductor with a small bandgap that can be tuned by external bias [47, 62]. This is one of the reasons for the multilayer graphene has recently attracted great interest.
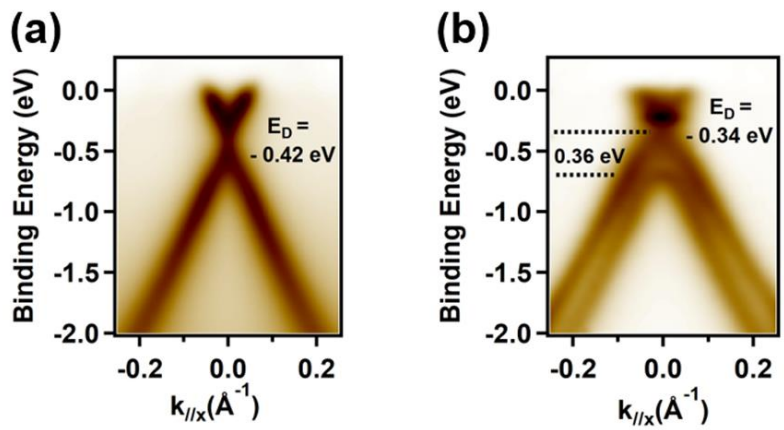

Figure 2.4. (a) Band structure of monolayer graphene grown on the Si-face 3C-SiC(111). (b) Band structure of bilayer graphene grown on the Si-face 3C-SiC(111) [10].

What will the band structures be like if we add more graphene layers? It has been reported that the electronic properties of multilayer graphene are strongly affected by its stacking sequence [63-66]. Trilayer graphene grown on $\mathrm{SiC}$ substrates would have two types of stacking sequences, $\mathrm{ABA}$ and $\mathrm{ABC}$. The rhombohedral (ABC stacking) graphene has shown its potential to introduce a flat band energy dispersion at the Dirac point, which would result in many exotic phases of matter such as superconductivity [63, 67-69]. Particularly, it has been reported that $3 \mathrm{C}$-SiC is beneficial for the growth of ABC-stacking trilayer graphene [67]. However, ABC is just the beginning of the rhombohedral stacking. Thick layer graphene $(>3 \mathrm{ML})$ might be formed in Bernal (ABAB), rhombohedral (ABCA), and turbostratic ( $\mathrm{ABCB}$ ) stacking sequences, as displayed in Fig. 2.5 for the case of 4ML graphene. 

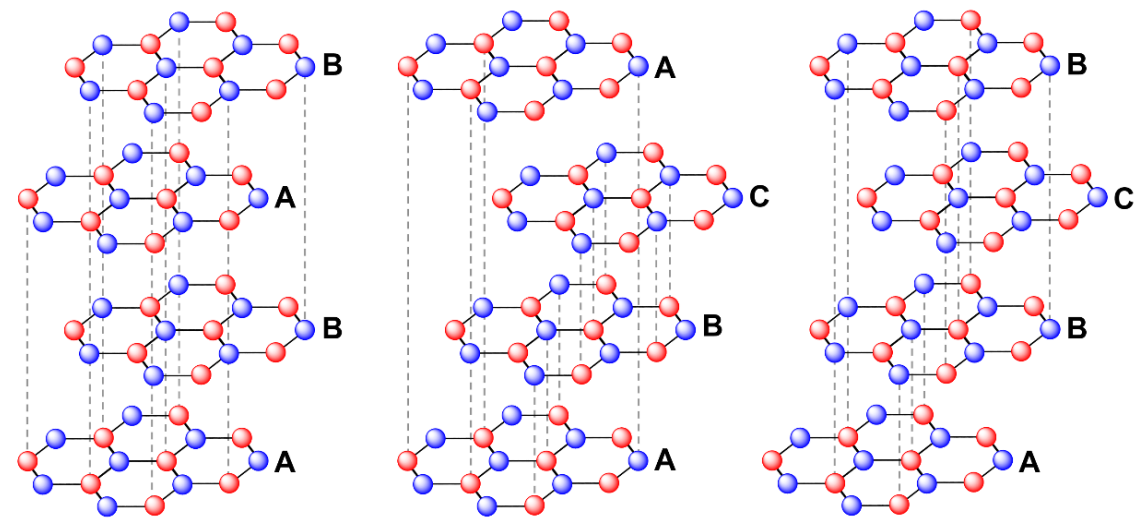

Figure 2.5. The atomic structures of four-layer graphene with Bernal (ABAB), rhombohedral (ABCA) and turbostratic $(\mathrm{ABCB})$ stacking sequences.

In this thesis, using ARPES in combination with theoretical calculations, we have comprehensively investigated the influence of stacking sequence on the electronic structure of four-layer graphene, which was grown on off-axis 3C-SiC(111) (Paper 5).

\subsection{Electronic properties of graphene grown on the $\mathrm{C}$-face SiC}

LEED patterns of multilayer graphene grown on the $\mathrm{C}$-face $\mathrm{SiC}$ always show multiple spots [13]. It may be either due to decoupled rotated graphene layers in the stack or rotational disorder within a single graphene layer. The main difference between these two scenarios is the stacking order of the graphene sheets. Usually decoupled layers have no rotational disorder inside the layer (only between the layers) and the diffraction pattern will not change with decreasing the sampling area. In this case, the multilayer graphene has a single linear dispersion and behaves like isolated graphene if the layers are decoupled in the stack [70-72]. This would explain the high mobility parameters of graphene grown on the $\mathrm{C}$-face $\mathrm{SiC}[14,73]$.

In contrast, the diffraction pattern will change while decreasing the sampling area if there are rotational disorders within a graphene layer. In this case, the multilayer graphene has the usual Bernal stacking $[11,12]$.

\subsection{Graphene nanoribbons}

Graphene nanoribbons (GNRs) possess opened band gap and thus have semiconducting properties due to quasi-one-dimensional quantum confinement and edge effects, which reveals 
the potential for nanoscale electronic devices [74-78]. Moreover, the bandgaps of GNRs largely depend on their widths. Precisely, the bandgaps are inversely proportional to the widths of GNRs [79, 80]. Several methods such as surface-assisted assembly of molecular precursors, chemical exfoliation, unzipping carbon nanotubes, as well as sublimation on a lithographically structured SiC substrate have been used for the fabrication of GNRs [74, 81-85]. Furthermore, GNRs might be directly prepared using a sublimation technique without any patterning or lithography. The growth mechanism is related to the fact that graphene starts to form at step edges of SiC preferentially where have the highest density of dangling bonds [86]. For example, it was reported that the bilayer graphene forms on the step facets while the monolayer graphene covers the (0001) terraces on off-oriented $4 \mathrm{H}-\mathrm{SiC}$ substrates [47, 74]. Moreover, it was found that the $(6 \sqrt{3} \times 6 \sqrt{3}) \mathrm{R} 30^{\circ}$ buffer layer only exists on the terraces but not on the step facets, instead, free-standing graphene forms on the step facets [87]. Such free-standing GNRs are good at supporting ballistic transport in epitaxial graphene [88, 89].

In this thesis work, we first grew $\sim 50 \mu \mathrm{m}$ thick $4 \mathrm{H}-\mathrm{SiC}$ epilayers on $4^{\circ}$ off-axis $4 \mathrm{H}-\mathrm{SiC}$ substrates by sublimation epitaxy. Large terraces/steps with inclined nanofacets in-between were induced by the step-bunching process during the epitaxy and used for the subsequent growth of GNRs. Using LEEM and STM techniques, we have studied the morphology of graphene over terraces/nanofacets and found that graphene is strongly buckled on the step facets and appears to be decoupled from the surface (Paper 4). 


\section{Solar-driven water splitting}

In the face of increasingly severe energy demand for human beings and environmental pollution problems, it is imperative to find suitable energy sources to replace traditional fossil fuels. Solar energy is the most plentiful, accessible and clean energy source. However, it is still challenging to harvest, convert, and store solar energy. The technology of photovoltaic solar cells is relatively mature now, but solar cells cannot work during nights and the storage of the electricity is still a problem. In this regard, solar-to-hydrogen energy conversion from water splitting is another emerging and sustainable way to utilize solar energy.

The energy density of hydrogen is $120 \mathrm{~J} / \mathrm{g}$, which is about three times that of gasoline and also higher than other commonly used fuels. Hydrogen has a clean by-product (water) when combusted for energy generation. It is also a facile fuel that can be used in different ways. For instance, it can be either converted into electricity via a fuel cell or operate an internal combustion engine directly. Therefore, photoelectrochemical (PEC) water splitting reveals its potential to convert abundant solar energy into the power that can be practically used.

\subsection{The principle of photoelectrochemical water splitting cell}

Fig. 3.1(a) shows a simplified diagram of PEC cell including a semiconductor photoanode, electrolyte, and a metal counter electrode [90]. The most important part of the PEC cell is the semiconductor photoanode which absorbs sunlight and converts the incident photons into electron-hole pairs. The basic principle for PEC water splitting is shown in Fig. 3.1(b) [90]. The electric field inside the semiconductor can spatially separate the photogenerated electrons and holes from each other. In the case of using an n-type semiconductor as a photoanode, the photogenerated electrons move toward the conducting contact of the semiconductor backside and are transported to the metal counter electrode via an external wire. The electrons participate in the reduction reaction at the counter-electrode to produce hydrogen gas. While the photogenerated holes move to the interface of semiconductor/electrolyte and participate in the oxidation reaction to produce oxygen gas.

In an alkaline electrolyte, the reduction and oxidation reactions can be written as follows:

$$
\begin{array}{cc}
4 \mathrm{H}_{2} \mathrm{O}+4 e^{-} \rightleftarrows 2 \mathrm{H}_{2}+4 \mathrm{OH}^{-} & E_{\text {red }}^{o}=-0.828 \mathrm{~V} \text { vs. NHE } \\
4 \mathrm{OH}^{-}+4 \mathrm{~h}^{+} \rightleftarrows 2 \mathrm{H}_{2} \mathrm{O}+\mathrm{O}_{2} & E_{o x}^{o}=-0.401 \mathrm{~V} \text { vs. NHE }
\end{array}
$$


(a)

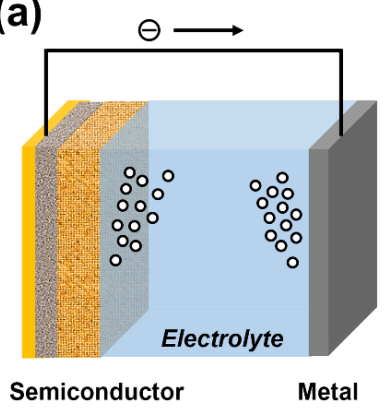

(b)

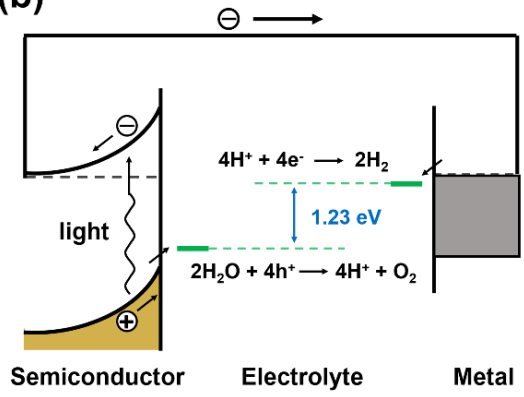

Figure 3.1. (a) A simplified diagram of the PEC cell. (b) The basic principle of PEC water splitting in the case of using an n-type semiconductor photoanode [90].

In an acidic electrolyte, we can subtract the dissociation reaction of water into protons and hydroxyl ions from formulas (4.1) and (4.2). Therefore, the reduction and oxidation reactions can be written as:

$$
\begin{gathered}
4 \mathrm{H}^{+}+4 e^{-} \rightleftarrows 2 \mathrm{H}_{2} \quad E_{\text {red }}^{o}=+0.000 \mathrm{~V} \text { vs. NHE } \\
2 \mathrm{H}_{2} \mathrm{O}+4 \mathrm{~h}^{+} \rightleftarrows 4 \mathrm{H}^{+}+\mathrm{O}_{2} \quad E_{\text {red }}^{o}=-0.828 \mathrm{~V} \text { vs. NHE }
\end{gathered}
$$

The variation of the Bibbs free energy for the overall water splitting should conform to the expression:

$$
\Delta G=-n F \Delta E
$$

The change of a Gibbs free energy will be $+237 \mathrm{KJ} / \mathrm{mol} \mathrm{H}_{2}$ if we substitute an electrochemical cell voltage of $-1.299 \mathrm{~V}$ at a standard temperature of $298 \mathrm{~K}$ and concentrations ( $1 \mathrm{~mol} / \mathrm{L}, 1 \mathrm{bar}$ ) into formula (2.5). This energy corresponds to a bandgap of $1.23 \mathrm{eV}$ for the semiconductor photoelectrode.

\subsection{Semiconductor criterions for PEC water splitting}

In the PEC cell, the semiconductor as a photoelectrode should satisfy several key requirements for effective water splitting including suitable bandgap, suitable band edge positions, high chemical stability, efficient charge transport, low cost, and low overpotentials [91].

The first requirement is the bandgap of the semiconductor. As discussed above, the required energy to split water is $1.23 \mathrm{eV}$. The thermodynamic losses during the PEC reaction are totally around $\sim 0.3-0.4 \mathrm{eV}[90,92]$. The overpotentials to ensure reaction kinetics are estimated to be $\sim 0.4-0.6 \mathrm{eV}[90,93]$. Considering these factors, the minimum bandgap of the 
semiconductor is limited by the sum of these three kinds of energies basically and is equal to $\sim 1.9 \mathrm{eV}$. This bandgap value corresponds to an absorption edge at $650 \mathrm{~nm}$. On the other hand, if the bandgap is larger than $3.1 \mathrm{eV}$, it cannot absorb most of the sunlight the intensity of visible light decreases dramatically below it. One previous work suggested that a maximum of the solar-to-hydrogen conversion efficiency of $16.8 \%$ can be obtained with an optimal (ideal) bandgap of $2.03 \mathrm{eV}$ [93].

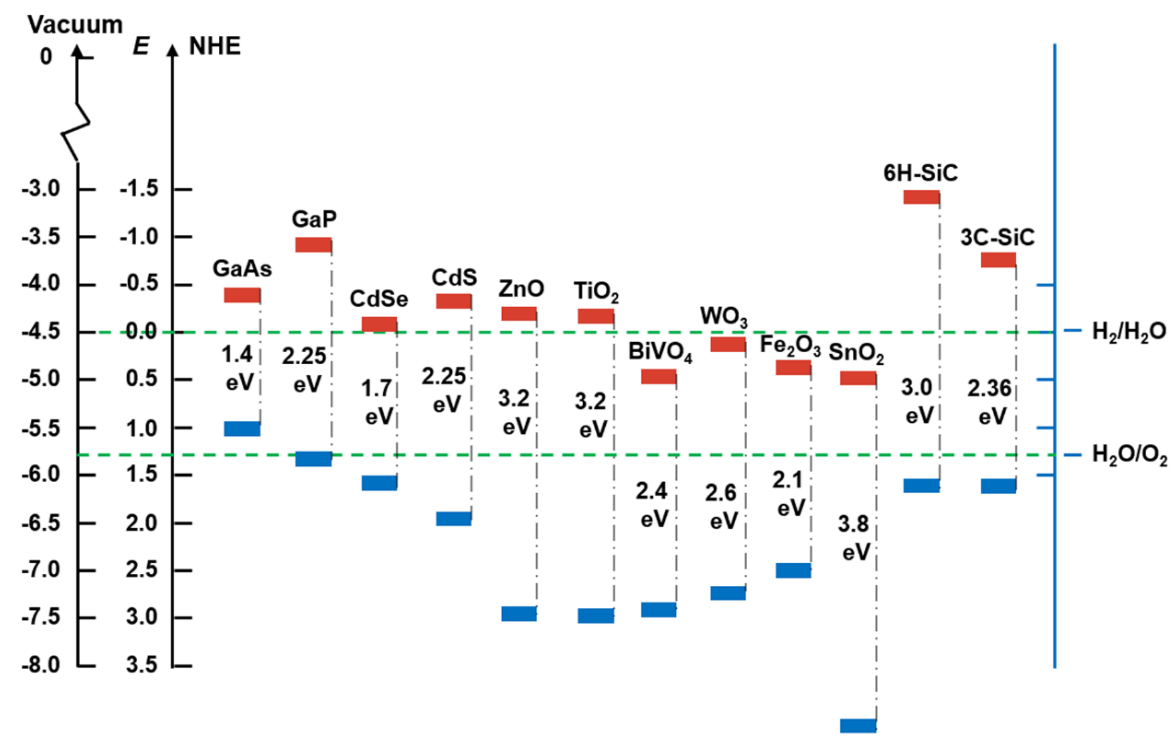

Figure 3.2. Band positions of several semiconductors in contact with aqueous electrolyte at $\mathrm{PH}=1$. The conduction and valence band edges of semiconductors are presented in red and blue, respectively, and are relative to either the vacuum electrode or the normal hydrogen electrode (NHE). Two green dashed lines indicate the reduction and oxidation potential of water. Adapted from ref. [94] with permission.

The second requirement, suitable band edges to straddle the water reduction and oxidation potentials, is the key parameter which determines the ability of the semiconductor for PEC water splitting. Specifically, as seen in Fig .3.2, the valence band of the semiconductor should be located below (more positive than) the oxidation potential $\mathrm{H}_{2} \mathrm{O} / \mathrm{O}_{2}$ and the conduction band edge should be located above (more negative than) the reduction potential $\mathrm{H}_{2} / \mathrm{H}_{2} \mathrm{O}$. This means that, in theory, such a semiconductor can spontaneously drive the redox reaction without the need of applying an external bias. For example, as displayed in Fig. 3.2, few semiconductors can satisfy this requirement. Semiconductors with too large bandgap (e.g. $\mathrm{TiO}_{2}, \mathrm{ZnO}$, and $6 \mathrm{H}-$ $\mathrm{SiC}$ ) would have a rather low PEC water-splitting performance. Some semiconductors with the conduction band edges more negative than water reduction potential $\mathrm{H}_{2} / \mathrm{H}_{2} \mathrm{O}$ can only reduce 
water, e.g. GaAs. In contrast, some semiconductors with valence band edges more positive than water oxidation potential $\mathrm{H}_{2} \mathrm{O} / \mathrm{O}_{2}$ can only oxidize water, such as $\mathrm{WO}_{3}, \mathrm{Fe}_{2} \mathrm{O}_{3}, \mathrm{SnO}_{2}$. Therefore, a PEC cell based on these oxide materials needs an external bias for driving water splitting.

The third requirement, high chemical stability against (photo-) corrosion of the semiconductor is another rigorous parameter that needs to be considered carefully. Many nonoxide semiconductors tend to be dissolved in the electrolyte because of their poor chemical stability. On the other hand, they may also form a thin oxide layer at the semiconductor/electrolyte interface which would significantly affect the charge transferability. For example, $\mathrm{CdS}, \mathrm{GaP}$, and $\mathrm{CdSe}$ have suitable semiconducting properties for solar-tohydrogen conversion, however, they may encounter the issues mentioned above.

The fourth requirement, the efficient charge transport, is also an important property to determine the overall performance of water splitting. A long lifetime/long diffusion length is beneficial for the photo-generated minority carries to reach the semiconductor/electrolyte interface before recombination. The carrier lifetime and diffusion length are related via $L_{\mathrm{D}}=$ $\sqrt{D \tau_{\mathrm{R}}}$. Where $\mathrm{D}$ is the diffusion coefficient and is related to the carrier mobility $\mu$, by the expression $D=K T \mu / e$. The diffusion length $L_{D}$ is usually in the range of several nanometers (in some oxides) to several hundred nanometers (in high-purity silicon). Metal oxides mostly have high electron mobility but low hole mobility. Some oxide materials $\left(\mathrm{TiO}_{2}, \mathrm{WO}_{3}\right)$ can satisfy this requirement. However, some semiconductors such as $\mathrm{Fe}_{2} \mathrm{O}_{3}$ have rather a poor carrier transport properties.

\subsection{C-SiC as photoanode for PEC water splitting}

First, 3C-SiC has an indirect bandgap of $2.36 \mathrm{eV}$ at room temperature, which can absorb a large part of sunlight as a photoanode. And its bandgap is larger than the required minimum energy value of $1.9 \mathrm{eV}$ for driving water splitting. Particularly, the bandgap of $3 \mathrm{C}$-SiC is very closed to the suggested optimal bandgap of $2.03 \mathrm{eV}$. This means that $3 \mathrm{C}-\mathrm{SiC}$ can give rise to a high solar-to-hydrogen conversion efficiency in principle.

Second, in contrast to $\mathrm{Fe}_{2} \mathrm{O}_{3}$, the conduction and valence band edges locate elegantly within the reduction and oxidation potentials of water splitting $3 \mathrm{C}-\mathrm{SiC}$, as seen in Fig. 3.2. This would, in principle, result in a spontaneous (without any external electric bias) water splitting at 3C-SiC photo-electrode. Indeed, this phenomenon has been demonstrated as reported in 2014 [95]. 
Third, like other n-type semiconductor photoanodes, the n-type 3C-SiC could also be oxidized during the PEC reaction. In the case of using n-type semiconductor photoanodes, photogenerated holes move to the semiconductor/electrolyte interface and participate in the oxidation reaction. Therefore, $3 \mathrm{C}-\mathrm{SiC}$ tends to be oxidized to form a $\mathrm{SiO}_{2}$ thin layer at the interface during the reaction. To solve this issue, a p-type $3 \mathrm{C}$-SiC is desired to be employed as the photocathode, at which photogenerated electrons reduce water to form hydrogen.

Considering the fourth requirement of the semiconductor for the PEC water splitting, 3C$\mathrm{SiC}$ has a relatively high electron mobility of $1000 \mathrm{~cm}^{2} / \mathrm{Vs}$ and hole mobility of $320 \mathrm{~cm}^{2} / \mathrm{Vs}$ (as given in Table 1, Chapter 1.3). 3C-SiC as a photoanode needs larger thickness to absorb all the incident light since its indirect bandgap, which means that photo-generated carriers have to move a longer distance before arriving the interface. From this perspective, high carrier mobility is an important advantage for $3 \mathrm{C}-\mathrm{SiC}$.

In this thesis work, we have investigated the PEC water splitting performance of the Siface and $\mathrm{C}$-face $3 \mathrm{C}$-SiC. We found that the surface polarity of $\mathrm{SiC}$ strongly influences the surface proton transfer and thus determines the water splitting performance. A more energyfavorable characterization has been demonstrated on the $\mathrm{Si}$-face $3 \mathrm{C}$-SiC, which allows its oxygen evolution reaction to operate at a very low overpotential (Paper 6). Moreover, we have designed a p-n junction photoanode by depositing p-type $\mathrm{NiO}$ nanoclusters on n-type $3 \mathrm{C}$-SiC and demonstrated an enhanced photovoltage and photocurrent with a reduction of the onset potential in the PEC solar-to-hydrogen conversion. The results reveal that the nanostructured $\mathrm{NiO} / 3 \mathrm{C}-\mathrm{SiC}$ p-n junction is a promising candidate for PEC water splitting application (Paper 7). 


\section{Characterization techniques}

\subsection{Nomarski Optical Microscopy}

Nomarski Differential Interference Contrast Microscopy (NDIC) is a common and efficient method to observe the surface topography of SiC crystals. The optical layout of the NDIC system is shown in Fig. 4.1(a), a prism is used to separate the polarized light source into two orthogonally polarized coherent portions that are spatially displaced (sheared) in the plane of the sample and recombine them after reflection off the sample surface. Two separated beams will have different path lengths when they reflect off the areas having different refractive index or thickness. They will interfere with each other and generate a pattern with different contrasts. Surface features such as tilted facet, structural defects, and different phases can be observed. For example, a large terrace, a few triangular defects, and micropipes are observed on the surface of a 3C-SiC sample in Fig. 4.1(b). Transparent samples can be studied using transmitted light mode. In this case, the light source is located below the sample. The unpolarized light passes through the objective and reach the detector finally. Such mode allows us to observe different SiC polytypes from the side view of the sample, as shown in Fig. 4.1(c).
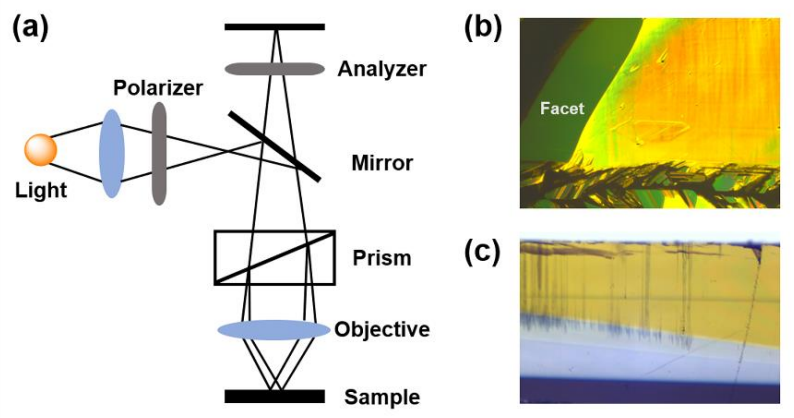

Figure 4.1. (a) The optical layout of the NDIC system. (b) Optical micrograph measured on the surface of a $3 \mathrm{C}-\mathrm{SiC}$ sample. (c) Optical micrograph of the side view of a 3C-SiC specimen.

\subsection{Atomic Force Microscopy}

Atomic Force Microscopy (AFM) is one of the most important methods for studying nanotechnology and material analysis. It has nanometer-scale resolution and can be easily operated. AFM uses the atomic force between the probe and the samples to know the surface topography of the sample. Fig. 4.2 shows a schematic illustration of an AFM. A microcantilever that is extremely sensitive to very weak forces is fixed at one end and has a bitty tip at the other 
end. The tip is in contact with the surface of the specimen lightly. Since there is a very weak repulsive force between atoms on the tip and atoms on the specimen surface, by controlling this force to be constant during scanning, the microcantilever with the tip will undulating motion perpendicular to the sample surface with respect to the equipotential surface of the force between the atoms. The position variation corresponding to each point of the scanning can be measured using the optical detection or the tunnel current detection method, which can amplify and convert the signal to obtain a three-dimensional topography image of the surface in atomic level.

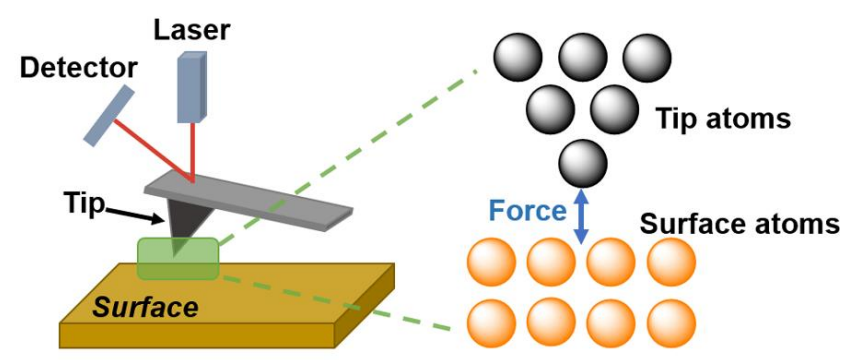

Fig. 4.2. Schematic illustration of an AFM setup.

There are three basic working modes, including non-contact, tapping, and contact modes. Contact and non-contact modes are susceptible to external factors, such as the attraction of water molecules, which induce image distortion issue caused by scratched surface and poor resolution. Therefore, there are restrictions in use, especially on biological and polymeric soft materials.

In tapping mode, the probe amplitude can be adjusted to have slightly intermittent jump contact with the surface, and the probe contacts the sample when it oscillates to the valley. The amplitude changes due to the fluctuation of the surface, and a topography image will be obtained by feedback control. The amount of pressure under the AFM probe can be viewed as an elastic effect that does not cause permanent damage along the $\mathrm{z}$-direction. In the $\mathrm{x} y$-direction, since the probe is intermittently beating, it does not cause permanent damage as the contact mode which drags in the $\mathrm{x} y$-direction.

Under the tapping mode operation, the measurement and feedback of the AFM will cause the phase change of the vibration probe due to the surface resistance and viscous force. The difference between the resisting force and the viscous force is originated from different material properties. Thus, this allows us to use the phase difference to observe material distribution 
qualitatively on the surface. When the composition of the surface is different, the jump frequency of the probe and the phase changes, so that different compositional properties can be observed.

In this thesis work, all of AFM images were measured in tapping mode. The AFM topography and phase images were collected simultaneously on the same measurement position. The line profiles generated in AFM topography images can give the terrace widths and step heights on $\mathrm{SiC}$ surfaces.

\subsection{Scanning Electron Microscopy}

Scanning Electron Microscopy (SEM) is an observation tool of microscopic morphology according to the interaction between the electron beam and matter. In principle, SEM uses a highly focused high-energy electron beam to scan a sample to excite various physical information. The surface topography of the test specimen is obtained by accepting, amplifying and imaging of the information. The brightness will be different on surface micro-regions where have different characteristics (such as morphology, atomic number, chemical composition, or crystal structure) under the action of the electron beam, results in a topography image with different contrast. The imaging signal is secondary electrons, backscattered electrons or absorbed electrons, of which secondary electrons are the main imaging signals. Secondary electrons refer to extranuclear electrons bombarded by incident electrons. Since the binding energy between the nucleus and the outer valence electron is small, when the extranuclear electron of the atom obtains energy that is larger than the corresponding binding energy from the incident electron, it can be detached from the atom to become a free electron. If this scattering process occurs in the vicinity of the sample surface, free electrons whose energy is larger than the work function of the material can escape from the surface and become free electrons in the vacuum, that are secondary electrons. The secondary electrons come from a 5$10 \mathrm{~nm}$ region below the surface with an energy of $0-50 \mathrm{eV}$. It is very sensitive to the surface state and can effectively observe the microscopic morphology of the sample surface. The resolution of the secondary electrons is relatively high, generally around $\sim 5-10 \mathrm{~nm}$.

One can also observe the fracture by using SEM. The fracture mode and mechanism of the material can be studied. In addition, looking at the fracture morphology, it is also possible to directly observe the fracturing source of the material, various defects, grain size, pore characteristics and distribution, microcrack morphology and grain boundary characteristics. 


\subsection{Scanning Tunneling Microscope}

Scanning Tunneling Microscope (STM) is an instrument that uses quantum tunneling effects to detect the surface structures of matters. The basic principle of STM is to use the atomic-scale probe and the surface of the sample as two electrodes. When the tip is very closed to the sample (usually less than $1 \mathrm{~nm}$ ), the electrons will pass through the barrier between the two electrodes and finally reach the other electrode under the applied electric field. The quantum tunneling effect causes the tunneling current to be exponentially related to the distance between surface atoms and the tip so that obtaining an atomic-scale surface topography image. In addition, STM can precisely manipulate a single molecule or atom at a low temperature by using the probe tip. Therefore, it is not only an important micro-nano-scale measurement tool but also a potential processing tool.

According to the different movement modes between the tip and the sample, STM has two working modes: constant height mode and constant current mode. For the constant height mode, the tip always scans at a certain level on the sample surface. The tunnel current changes continuously as the surface rises and falls. The obtained STM image not only outlines the geometry of the atoms on the surface but also reflects the electronic structural features of the atoms. For the constant current mode, the tunnel current is maintained constant with the constant bias during the scanning. Since the tip moves up and down with the undulation of the surface, it does not hit the surface due to large surface undulation. Thus, the constant current mode is suitable for observing samples with large surface undulations.

STM has many advantages compared to AFM or SEM. For example, the experiment can be carried out in a few environments: atmospheric, ultra-high vacuum or liquid. The operating temperature range is wide and can vary from a few $\mathrm{mK}$ to $1100 \mathrm{~K}$. This is currently not possible for any other microscopy technologies. The resolution is very high and can achieve $0.1 \mathrm{~nm}$ laterally and $0.01 \mathrm{~nm}$ perpendicularly. Therefore, individual atoms and a three-dimensional structural image of atoms on the surface can be directly observed. The scanning tunneling spectrum (STS) of the surface can be obtained during measurement.

Fast Fourier transform (FFT) is a special integral transformation, which can express a function satisfying certain conditions as a linear combination or integration of sinusoidal basis functions. In different research fields, Fourier transform has many different variants, such as continuous Fourier transform and discrete Fourier transform. In the purely mathematical sense, Fourier transform is to transform a function into a series of periodic functions. From the 
physical effect, the Fourier transform is to transform the image from the spatial sphere to the frequency sphere, and its inverse transform is to transform the image from the frequency sphere to the spatial sphere. Fourier transform can resolve interference, diffraction and imaging problems nowadays. It can be used to calculate the intensity distribution of a single slit and circular aperture diffraction. According to the calculation results, the single slit and circular aperture diffraction and intensity distribution are simulated by software and thus a diffraction pattern can be obtained.

\subsection{Low Energy Electron Microscopy}

Low Energy Electron Microscopy (LEEM) is a powerful tool to image epitaxial growth, surface reconstructions, self-organization, et al. In this thesis, LEEM was used to analyze graphene layers grown on SiC substrates. In LEEM measurements, electrons with high energy are emitted from an electron gun toward the sample surface. When the electrons approach the surface, they are decelerated by an electric field and reaching the surface with low energy of 0 $100 \mathrm{eV}$. Elastically backscattered electrons, which are low energy electrons that are reflected from the sample surface without energy loss, are utilized for surface imaging. The different diffraction intensities of electrons which are related to both the surface morphology and thickness of graphene layers contribute to the different contrast in a LEEM image. Low energy electrons act as waves with de Broglie wavelength which is commensurate with the atomic distances in crystal materials. Hence, the best resolution can reach few nanometers so far.
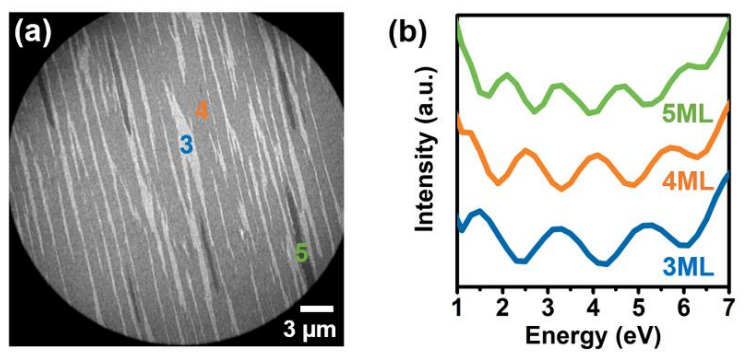

Fig. 4.3. (a) LEEM image (field of view $=30 \mu \mathrm{m}$ ) of the graphene grown on off-axis 3C-SiC(111), showing 3-5 ML graphene. (b) The electron reflectivity curves collected on the colorfully labeled region in (a).

Observing the contrast in a LEEM image in combination with the corresponding electron reflectivity curve (so-called I-V curve), one can determine the number of layers and obtain their 
coverage or uniformity. The number of graphene layers is determined by the number of minima in the I-V curve [96], as seen in Fig. 4.3. The reason is that in thin graphene films, the conduction bands have discrete energy levels along the direction perpendicular to the film. When the energy of incident electron matches with one of the discrete energy levels, the electron can resonantly pass through the graphene film, which will reduce the electron reflectivity and thus give a "valley" in the I-V curve.

Other surface analysis and measurement devices may also be configured in the microscopy, such as low energy electron diffractometer (LEED). LEED is the principal method to determine the surface structures of solids. Fig. 4.4(a) shows an experimental setup. The electron gun provides electrons with low energy of $20-200 \mathrm{eV}$, which bombards the crystal surface. The diffraction pattern is only generated by the back-scattered electrons. The secondary electrons are filtered by the grids placed in the front of the fluorescent screen.
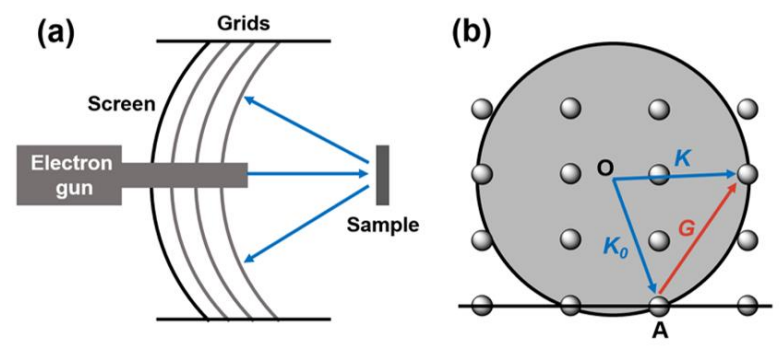

Fig. 4.4. (a) A brief setup of a LEED experiment. (b) Ewald's sphere construction.

The diffraction pattern can be generated when the difference between the scattered wave vector $K$ and the incident wave vector $K_{0}$ is exactly equal to a reciprocal vector in the reciprocal space lattice. $\vec{K}-\overrightarrow{K_{0}}=\overrightarrow{G_{h k l}}$. Not all diffraction points appear on all reciprocal points since $K_{0}$ is a certain value. Only the reciprocal points that satisfy the above equation can appear diffraction maximum. This diffraction condition is the Laue expression of LEED. For example, A beam of electrons is incident on the surface of the sample that to be tested, drawing a vector parallel to the incident electron beam with a length of $2 \pi / \lambda$, is the incident wave vector $\overrightarrow{O A}$, $K_{0}=\overrightarrow{O A}$. And then using A as the origin to draw a reciprocal lattice. There is no energy loss because of the elastic scattering. Making a sphere with the center $O$ and $2 \pi / \lambda$ as the radius, the vector $\mathrm{K}$ connecting the center $\mathrm{O}$ and any point on the sphere represents the wave vector of the elastic scattering electrons that may occur. This ball is so-called the Ewald sphere, as shown in Fig. 4.3(b). 


\subsection{Angle-Resolved Photoemission Spectroscopy}

Angle-resolved photoemission spectroscopy (ARPES) is a method of directly observing the electronic structure of a solid. It employs a very high energy photon to illuminate a solid and observe the scattering of electrons. It can give different information about the occupying state (including the surface state) of valence electrons, such as the density distribution of states, the dispersion of the energy band in the wave vector space, and the symmetry of the wave function. It can not only get the structure of density of states (DOS) but also "sketch" the shape of the band structure according to the relationship between the peak position and the angle. The band dispersion relationship can be obtained since ARPES can measure the photoelectron energy and wave vector of the solid surface simultaneously.

The most widely used analyzer currently measures the photoelectron number as a function of its exit angle (electron momentum) and exit kinetic energy. Using the law of conservation of kinetic energy and momentum, we can calculate the kinetic energy and momentum of electrons in the sample. The law of conservation of energy can be expressed as $E_{k i n}=\hbar \omega-E_{B}-\varphi$, where $\hbar \omega$ is the incident light energy, $E_{k i n}$ is the outgoing photoelectron kinetic energy, $\varphi$ is the material work function (the minimum photon energy to remove electrons from the sample into the vacuum), and $E_{B}$ is the electron binding energy relative to the Fermi surface.

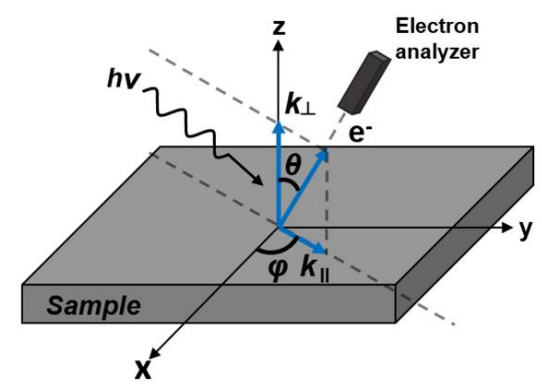

Fig. 4.5. Schematic illustration of an ARPES setup.

The crystal translational symmetry is disrupted perpendicular to the surface of the sample, resulting in momentum that is no longer conserved in this direction. However, the momentum component of the electrons parallel to the surface of the sample is preserved. Therefore, we can only get the parallel momentum component. The law of conservation of momentum parallel to the surface of the sample can be expressed as $k_{\|}=\sqrt{\frac{2 m E_{k i n}}{\hbar}} \sin \theta$, where $\theta$ is the emission angle and $k_{\|}$is parallel momentum of the electron in the crystal, as seen in Fig. 4.5. By correlating 
the obtained energy with the momentum, the dispersion relation of the electrons in the crystal can be obtained. At the same time, ARPES can also obtain the energy density curve and the momentum density curve, and directly give the Fermi surface of the solid.

To study graphene layers grown on SiC using ARPES, one can know the electronic structure of graphene layers and investigated stacking sequences, the shape, and curvature of the band structure near the Fermi level.

\subsection{Raman Spectroscopy}

Raman Spectroscopy is a kind of scattering spectrum, which is based on the Raman scattering effect. It analyzes the scattering spectrum generated from different incident light frequency to obtain molecular vibration and rotation information and is applied to the analysis of the molecular structure.

Elastic scattering and inelastic scattering occur when light is irradiated onto the material. The scattered light of elastic scattering has the same wavelength as the excitation light. The scattered light of inelastic scattering has a longer and shorter wavelength than the excitation light, collectively referred to as the Raman effect. When a gas, liquid or transparent sample is irradiated with monochromatic light having a wavelength much smaller than the particle size of the sample, most of the light is transmitted in the original direction while a small portion is scattered at different angles, forming a scattered light. When observing in the vertical direction, in addition to Rayleigh scattering with the same frequency as the original incident light, there are a series of symmetrically distributed Raman lines with very weak displacements of the incident light. The number of Raman lines, the magnitude of the shift, the length of the line is directly related to the vibrational or rotational energy level of the molecule in the sample. Therefore, Raman spectroscopy can help to obtain information about the vibration or rotation of molecules.

In this thesis work, Raman spectroscopy was used to confirm the polytypes in SiC samples. A typical Raman spectrum of $\mathrm{SiC}$ exhibits four modes: folded modes of transverse acoustic (FTA) and optic (FTO) and folded modes of longitudinal acoustic (FLA) and optic (FLO) [97]. These four modes have been observed for various $\mathrm{SiC}$ polytypes [97]. By comparing peak positions of the measured spectrum to standard spectrums of $\mathrm{SiC}$, one can determine the $\mathrm{SiC}$ polytypes [98]. 
Raman spectroscopy was also used to characterize graphene layers grown on $\mathrm{SiC}$. Fig. 4.6 shows a subtracted Raman spectrum of the monolayer graphene. The D, G, and 2D band are typical features of graphene. $\mathrm{G}$ peak located around $1600 \mathrm{~cm}^{-1}$ originates from first-order Raman scattering process in the Brillouin zone. 2D peaking located around $2730 \mathrm{~cm}^{-1}$ originates from the second-order process $[99,100]$.

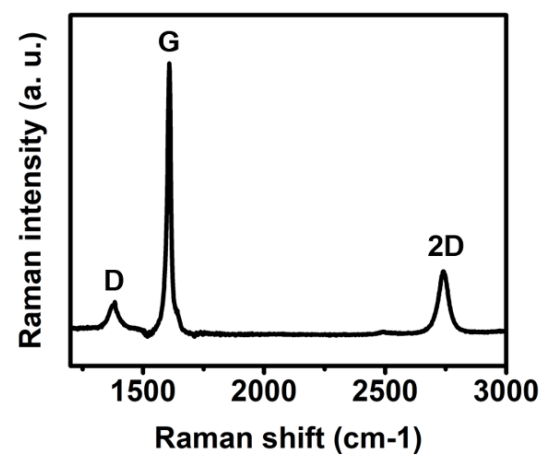

Fig. 4.6. A typical subtracted Raman spectrum of monolayer graphene grown on 3C-SiC(111).

A single Lorentz 2D peak having a FWHM of $30-40 \mathrm{~cm}^{-1}$ corresponds to the feature of single-layer graphene. The $\mathrm{G}$ band is sensitive to the doping concentration, which changes the electronic band structure of graphene grown on $\mathrm{SiC}$. The shift of the 2D band largely depends on the compressive strain originated from the mismatch between epitaxial graphene and $\mathrm{SiC}$ substrate, which remarkably reveals the change of graphene layers [101]. If the 2D peak is asymmetric, it implies that the $2 \mathrm{D}$ peak includes several components coming from different stacking sequences, suggesting the presence of multilayer graphene [99]. Calculating the integral intensity ratio of the $\mathrm{G}$ band and $2 \mathrm{D}$ band is another way to estimate the number of graphene layers [102]. The D-peak at $1360 \mathrm{~cm}^{-1}$ originates from disordered vibration in graphene representing the existence of defects or disorders [103].

The reflectance mapping was used to estimate the number of graphene layers over a large area on the sample, as previously proposed [104]. The power of the reflected laser beam from graphene layers with different thickness will be different. It was found that the reflectance intensity of graphene layer grown on SiC linearly increases about $\sim 1.7 \%$ per layer, normalized to the bare substrate [104]. Reflectance mapping can be measured simultaneously with Raman mapping. It can give a fast determination of graphene layers grown on $\mathrm{SiC}$ substrates. 


\subsection{X-ray Diffraction}

$\mathrm{X}$-ray diffraction (XRD) is one of the non-destructive techniques to analyze all kinds of matter-ranging from crystals, powders, fluids. X-rays are electromagnetic waves with very short wavelengths, usually a few $\AA$, which are equivalent to the atomic spacing of crystals. When X-rays are incident on a series of parallel lattice planes at an angle $\theta$, the diffraction waves that pass in a certain direction will be enhanced by constructive interference and will be weakened by destructive interference in other directions, as shown in Fig. 4.7.

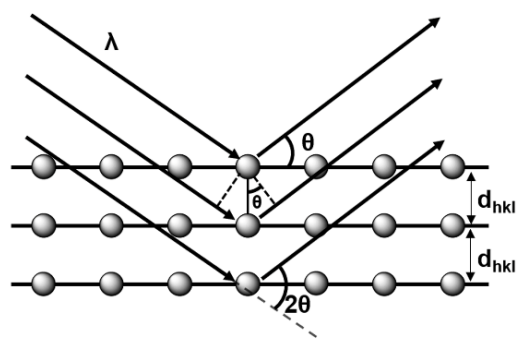

Fig. 4.7. Schematic illustration of diffraction geometry from the lattice planes.

If the incident wavelength is constant, the incident angle and the interplanar spacing will satisfy a certain relationship, $n \lambda=2 d \sin \theta$, which is called the Bragg diffraction relationship, where $n$ is an integer, $\lambda$ is the wavelength, $\mathrm{d}$ is the interplanar spacing between rows of atoms and $\theta$ is the diffraction angle. The interplanar spacing between the lattices, the type and size of the unit cell can be obtained by measuring the incident angle when the diffraction wave is enhanced. The XRD pattern is a transformation of the crystal structure of the substance essentially. Each crystal structure corresponds to a diffraction pattern and does not change due to mixing with other substances. If compared the measured diffraction pattern to a standard pattern, the specific composition of the measured phase can be determined. Therefore, XRD analysis has become the basic method for qualitative analysis of phase components.

High-resolution $\omega$ rocking curve technique can be employed to figure out strong textures and diffraction pattern with only a few reflections. In this mode, the diffractometer operates with decoupled $\theta$ and $2 \theta$. To obtain a rocking curve, first, one needs to find the $2 \theta$ angle corresponding to the tested material under the condition of satisfying the Bragg diffraction. Then, the detector on the $2 \theta$ circle is fixed to this $2 \theta$ angle while the sample is slightly tiled (rocked) in the vicinity of the Bragg angle $\theta$. Thus, the angle $\theta$ and $2 \theta$ and are decoupled and the is angle $\theta$ so-called $\omega$ with respect to its independent variation. 
The crystalline quality can be evaluated by the full width at half maximum (FWHM) of the $\omega$ peak. The sharp $\omega$ peak indicates high crystalline quality. If there are many microdomains or crystallographic planes which are slightly tiled to each other on the surface, the $\omega$ peak will be wider (larger FWHM value) and even have several sub-peaks.

\subsection{Photoluminescence Spectroscopy}

Photoluminescence Spectroscopy (PL) is a non-destructive technique that can quickly and easily characterize defects, impurities and luminescence properties of semiconductor materials. When a substance is excited by light, an applied electric field, or an electron beam bombardment, it absorbs external energy resulting in its electrons are in an excited state. As long as the substance does not undergo chemical changes, when the external excitation stops, the electrons in the excited state always return to the ground state. In this process, a portion of the excess energy is released by light or heat. If this part of the energy is emitted in the form of electromagnetic waves of light, it is called luminescence. In general, luminescence is the process by which the inside of a substance absorbs energy in some way and emits excess energy in the form of light radiation other than heat radiation. Luminescence caused by excitation of light is called photoluminescence. The electrons and holes are combined to emit light to form an energy distributed spectrum of light with different wavelengths. By comparing the obtained spectrum with the standard spectrum of a semiconductor, one can know the polytype of the tested semiconductor. The doping concentration can be estimated, and the crystalline quality of the tested sample can be evaluated as well. 


\section{Summary of papers}

\section{Paper I}

We have comparatively studied the growth of C-face and Si-face $3 \mathrm{C}$-SiC on $4{ }^{\circ}$ off-oriented 4H-SiC substrates using sublimation epitaxy and obtained a $1 \mathrm{~mm}$-thick $\mathrm{C}$-face $3 \mathrm{C}$-SiC over a large single-domain without double positioning boundaries by the lateral enlargement method. The high-resolution XRD and low-temperature photoluminescence results demonstrate that Cface $3 \mathrm{C}-\mathrm{SiC}$ exhibits a high crystalline quality, which is comparable with the quality of the $\mathrm{Si}$ face 3C-SiC. Moreover, we have found that for both the C-face and Si-face 3C-SiC, a 4H-SiC homoepitaxial layer and a polytype-transition layer are formed before the formation of the $3 \mathrm{C}$ $\mathrm{SiC}$ layer. However, the transition layer in the $\mathrm{C}$-face $3 \mathrm{C}-\mathrm{SiC}$ sample is not enlarged as much as in the Si-face sample along the step-flow direction, thus resulting in less density of defects at the edge on the $\mathrm{C}$-face $3 \mathrm{C}$-SiC compared to the Si-face $3 \mathrm{C}$-SiC. Therefore, a quite consistent crystalline quality over the entire $\mathrm{C}$-face $3 \mathrm{C}$-SiC sample was demonstrated, which facilitates the growth of $3 \mathrm{C}-\mathrm{SiC}$ on hexagonal $\mathrm{SiC}$ substrates by lateral enlargement.

\section{Paper II}

We have systematically investigated the growth of monolayer and multilayer graphene on the Si-face off-axis 3C-SiC(111), which exhibits periodic steps as nucleation sites for the growth of graphene. We have found that the step bunching on the Si-face of 3C-SiC(111) can be fully eliminated during graphene growth. As a result, the large-area monolayer, bilayer, and fourlayer graphene can be controllably grown via tuning the growth temperature and duration at the constant temperature. Particularly, homogeneous four-layer graphene over areas of tens of square micrometers was demonstrated by low energy electron microscopy. Based on the identical decomposition energy of the $3 \mathrm{C}$-SiC steps, we also propose a growth model to explain the elimination process of the step bunching and the formation of graphene layers on the $\mathrm{Si}$ face off-axis $3 \mathrm{C}-\mathrm{SiC}(111)$.

\section{Paper III}

We have investigated the growth of graphene layers on the off-axis C-face $3 \mathrm{C}-\operatorname{SiC}(\overline{1} \overline{1} \overline{1})$ by sublimation epitaxy. We have obtained a few graphene domains with different thickness ranging from one monolayer (ML) to four ML without the buffer layer. In particular, we demonstrate the growth of large graphene domains over several square micrometers, which enable us to measure $\mu$-LEED on a single domain separately. As a result, we have discovered 
the presence of mainly four rotational grains within the monolayer graphene. Two sets of graphene $(1 \times 1)$ spots that are rotated $30^{\circ}$ with respect to each other are observed on bilayer graphene, and a series of small azimuthal rotational spots ranging from around $4 \sim 7^{\circ}$ are also observed. The Raman spectra collected on graphene domains show small D peaks, indicating high crystalline quality graphene layers grown on the $\mathrm{C}$-face off-axis $3 \mathrm{C}-\mathrm{SiC}(\overline{1} \overline{1} \overline{1})$.

\section{Paper IV}

We report a pattern-free approach for the growth of free-standing graphene nanoribbons (GNRs) by using the bunched steps formed on off-oriented $4 \mathrm{H}-\mathrm{SiC}$ (0001) epilayers. We first grew $\sim 50$ $\mu \mathrm{m}$-thick $4 \mathrm{H}-\mathrm{SiC}(0001)$ epilayers on $4^{\circ}$ off-axis $4 \mathrm{H}-\mathrm{SiC}$ substrates by sublimation epitaxy. Large terraces/steps with inclined nanofacets in-between, induced by the step-bunching process during the epilayer growth, used for the subsequent sublimation growth of GNRs. Scanning tunneling microscopy (STM) profiles reveal the inclined angles of step facets, which are independent on the step heights and are similar to the previously reported angles of the faceted sidewalls produced by lithography. Using low energy electron microscopy (LEEM) and diffraction (LEED) measurements, we have shown that the terraces are mainly covered by monolayer graphene with buffer layer underneath it. By the STM study and the analysis of their Fourier transform patterns, we have found that graphene is strongly buckled on the step facets and appears to be decoupled from the surface.

\section{Paper V}

By the analysis of angle-resolved photoelectron spectroscopy (ARPES) measurements in combination with theoretical calculations, we have comprehensively investigated the influence of the stacking sequence and the interlayer spacing on the electronic structure of four-layer graphene grown on the off-axis 3C-SiC(111). LEEM measurements confirmed the number of graphene layers and their coverage on 3C-SiC(111) surface. Large coverage of four-layer graphene permits us to measure ARPES on it. Different band structures for ABAB (Bernal), $\mathrm{ABCA}$ (rhombohedral), and $\mathrm{ABCB}$ (turbostratic) stacking sequences were calculated by Firstprinciples density functional theory. By comparing with ARPES results, we have demonstrated the presence of a rhombohedral stacking sequence in four-layer graphene and a nearly dispersionless electronic band (flat band) with a width of $\sim 0.07 \AA$ near the Fermi level. Furthermore, we have found that the interlayer spacing determines the bandgap, width of flat band, and curvature of the flat-band region, which could play an important role in the research of superconductivity in rhombohedral multilayer graphene. 


\section{Paper VI}

We have studied the effect of the surface polarity of $\mathrm{SiC}$ on the performance of the photoelectrochemical water splitting. On the $\mathrm{C}$-face $\mathrm{SiC}$, proton-coupled electron transfer controls the interfacial hole transfer for water oxidation, giving rise to energy loss because of the highly activated proton-transfer steps. While on the Si-face $\mathrm{SiC}$, a surface-catalyzed barrierless $\mathrm{O}-\mathrm{H}$ breaking can be achieved with a facile proton exchange and migration feature. As a result, the $\mathrm{Si}$-face $\mathrm{SiC}$ facilitates the oxygen evolution reaction at a very low overpotential. This would shed light on the design of photoelectrodes for zero-biased solar water splitting by surface engineering.

\section{Paper VII}

We introduced a p-n junction photoanode by depositing p-type $\mathrm{NiO}$ nanoclusters on $\mathrm{n}$-type $3 \mathrm{C}$ $\mathrm{SiC}$ and demonstrated a significantly enhanced photoelectrochemical (PEC) water splitting performance. We have demonstrated that such a p-n junction photoanode exhibits a low onset potential of $0.20 \mathrm{~V}$ versus reversible hydrogen electrode $\left(\mathrm{V}_{\mathrm{RHE}}\right)$, a high photovoltage of $1.0 \mathrm{~V}$, a photocurrent density of $1.01 \mathrm{~mA} \mathrm{~cm}^{-2}$ at $0.55 \mathrm{~V}_{\mathrm{RHE}}$, and a high fill factor of $0.57 \%$. We show that the $\mathrm{NiO} / 3 \mathrm{C}-\mathrm{SiC}$ heterojunction facilitates the separation of photogenerated carriers and suppresses carrier recombination. Moreover, the $\mathrm{NiO}$ nanostructured layer also protects the $3 \mathrm{C}$ $\mathrm{SiC}$ surface against photo-corrosion. 


\section{References}

[1] N. Zheludev, The life and times of the LED-a 100-year history, Nat. Photonics 1 (2007) 189-192.

[2] W.J. Choyke, D.R. Hamilton, L. Patrick, Optical Properties of Cubic SiC: Luminescence of NitrogenExciton Complexes, and Interband Absorption, Phys. Rev. 133 (4A) (1964) A1163-A1166.

[3] V. Cimalla, J. Pezoldt, O. Ambacher, Group III nitride and SiC based MEMS and NEMS: materials properties, technology and applications, J. Phys. D: Appl. Phys. 40 (20) (2007) 6386-6434.

[4] C.E. Weitzel, J.W. Palmour, H. Calvin, J. Carter, K. Moore, K.J. Nordquist, S. Allen, C. Thero, M. Bhatnaga, Silicon Carbide High-Power Devices, IEEE Trans. Electron Devices 43 (10) (1996) 1733-1741.

[5] A. Fissel, Artificially layered heteropolytypic structures based on SiC polytypes: molecular beam epitaxy, characterization and properties, Phys. Rep. 379 (3-4) (2003) 149-255.

[6] M.E. Levinshtein, S.L. Rumyantsev, M.S. Shur, Properties of advanced semiconductor materials GaN, AlN, $\mathrm{SiC}, \mathrm{InN}, \mathrm{BN}, \mathrm{SiC}, \mathrm{SiGe}$, John Wiley \& Sons, Inc. ISBN 0-471-35827-4 (2001).

[7] J. Lu, C.I. Thomas, M.V.S. Chandrashekhar, M.G. Spencer, Measurement of spontaneous polarization charge in $\mathrm{C}$-face $3 \mathrm{C}-\mathrm{SiC} / 6 \mathrm{H}-\mathrm{SiC}$ heterostructure with two-dimensional electron gas by capacitance-voltage method, J. Appl. Phys. 105 (10) (2009) 106108.

[8] J. Lu, M.V.S. Chandrashekhar, J.J. Parks, D.C. Ralph, M.G. Spencer, Quantum confinement and coherence in a two-dimensional electron gas in a carbon-face $3 \mathrm{C}-\mathrm{SiC} / 6 \mathrm{H}-\mathrm{SiC}$ polytype heterostructure, Appl. Phys. Lett. 94 (16) (2009) 162115.

[9] Y. Shi, A.A. Zakharov, I.G. Ivanov, G.R. Yazdi, V. Jokubavicius, M. Syväjärvi, R. Yakimova, J. Sun, Elimination of step bunching in the growth of large-area monolayer and multilayer graphene on off-axis 3C SiC (111), Carbon 140 (2018) 533-542.

[10] W. Wang, Y. Shi, A.A. Zakharov, M. Syvajarvi, R. Yakimova, R.I.G. Uhrberg, J.W. Sun, Flat-Band Electronic Structure and Interlayer Spacing Influence in Rhombohedral Four-Layer Graphene, Nano Lett. 18 (2018) 5862-5866.

[11] L.I. Johansson, R. Armiento, J. Avila, C. Xia, S. Lorcy, I.A. Abrikosov, M.C. Asensio, C. Virojanadara, Multiple pi-bands and Bernal stacking of multilayer graphene on $\mathrm{C}$-face $\mathrm{SiC}$, revealed by nano-Angle Resolved Photoemission, Sci. Rep. 4 (2014) 4157.

[12] L.I. Johansson, S. Watcharinyanon, A.A. Zakharov, T. Iakimov, R. Yakimova, C. Virojanadara, Stacking of adjacent graphene layers grown on C-face SiC, Phys. Rev. B 84 (12) (2011) 125405.

[13] C. Bouhafs, V. Stanishev, A.A. Zakharov, T. Hofmann, P. Kühne, T. Iakimov, R. Yakimova, M. Schubert, V. Darakchieva, Decoupling and ordering of multilayer graphene on C-face 3C-SiC(111), Appl. Phys. Lett. 109 (20) (2016) 203102.

[14] J.L. Tedesco, B.L. VanMil, R.L. Myers-Ward, J.M. McCrate, S.A. Kitt, P.M. Campbell, G.G. Jernigan, J.C. Culbertson, C.R. Eddy, D.K. Gaskill, Hall effect mobility of epitaxial graphene grown on silicon carbide, Appl. Phys. Lett. 95 (12) (2009) 122102. 
[15] J. Jian, Y. Shi, S. Ekeroth, J. Keraudy, M. Syväjärvi, R. Yakimova, U. Helmersson, J. Sun, A nanostructured $\mathrm{NiO} /$ cubic SiC p-n heterojunction photoanode for enhanced solar water splitting, J. Mater. Chem. A 7 (9) (2019) 4721-4728.

[16] M. Syvajarvi, Q.B. Ma, V. Jokubavicius, A. Galeckas, J.W. Sun, X.Y. Liu, M. Jansson, P. Wellmann, M. Linnarsson, P. Runde, B.A. Johansen, A. Thogersen, S. Diplas, P.A. Carvalho, O.M. Lovvik, D.N. Wright, A.Y. Azarov, B.G. Svensson, Cubic silicon carbide as a potential photovoltaic material, Sol. Energy Mater. Sol. Cells 145 (2016) 104-108.

[17] N. Yang, H. Zhuang, R. Hoffmann, W. Smirnov, J. Hees, X. Jiang, C.E. Nebel, Nanocrystalline 3C-SiC Electrode for Biosensing Applications, Anal. Chem. 8 3(15) (2011) 5827-5830.

[18] C.L. Frewin, M. Reyes, J. Register, S.W. Thomas, S.E. Saddow, 3C-SiC on Si: A Versatile Material for Electronic, Biomedical and Clean Energy Applications, MRS Proceedings 1693 (2014).

[19] V. Jokubavicius, G.R. Yazdi, R. Liljedahl, I.G. Ivanov, J.W. Sun, X.Y. Liu, P. Schuh, M. Wilhelm, P. Wellmann, R. Yakimova, M. Syväjärvi, Single Domain 3C-SiC Growth on Off-Oriented 4H-SiC Substrates, Cryst. Growth Des. 15 (6) (2015) 2940-2947.

[20] M.H. Hong, A.V. Samant, P. Pirouz, Stacking fault energy of 6H-SiC and 4H-SiC single crystals, Philos. Mag. A 80 (4) (2009) 919-935.

[21] H. Matsunami, S. Nishino, T. Tanaka, HETEROEPITAXIAL GROWTH OF $\beta$-SiC ON SILICON SUBSTRATE USING SiCI $4-\mathrm{C}_{3} \mathrm{H}_{8}-\mathrm{H}_{2}$ SYSTEM, J. Cryst. Growth 45 (1978) 138-143.

[22] S. Nishino, J.A. Powell, H.A. Will, Production of large-area single-crystal wafers of cubic SiC for semiconductor devices, Appl. Phys. Lett. 42 (5) (1983) 460-462.

[23] A. Severino, R. Anzalone, M. Camarda, N. Piluso, F. La Via, Structural Characterization of Heteroepitaxial 3C-SiC, Materials Science Forum 711 (2012) 27-30.

[24] R. Vasiliauskas, M. Marinova, P. Hens, P. Wellmann, M. Syväjärvi, R. Yakimova, Nucleation Control of Cubic Silicon Carbide on 6H- Substrates, Cryst. Growth \& Des. 12 (1) (2011) 197-204.

[25] M. Soueidan, G. Ferro, O. Kim-Hak, F. Cauwet, B. Nsouli, Vapor-Liquid-Solid Growth of 3C-SiC on rSiC Substrates. 1. Growth Mechanism, Cryst. Growth Des. 8 (3) (2008) 1044-1050.

[26] T. Furusho, M. Sasaki, S. Ohshima, S. Nishino, Bulk crystal growth of cubic silicon carbide sublimation epitaxy, J. Crystal Growth 249 (2003) 216-221.

[27] V. Jokubavicius, G.R. Yazdi, R. Liljedahl, I.G. Ivanov, R. Yakimova, M. Syväjärvi, Lateral Enlargement Growth Mechanism of 3C-SiC on Off-Oriented 4H-SiC Substrates, Cryst. Growth Des. 14 (12) (2014) 6514-6520.

[28] O. Kim-Hak, G. Ferro, J. Dazord, M. Marinova, J. Lorenzzi, E. Polychroniadis, P. Chaudouët, D. Chaussende, P. Miele, Study of the $3 \mathrm{C}-\mathrm{SiC}$ nucleation from a liquid phase on a $\mathrm{C}$ face $6 \mathrm{H}-\mathrm{SiC}$ substrate, $\mathrm{J}$. Cryst. Growth 311 (8) (2009) 2385-2390.

[29] M. Soueidan, G. Ferro, A Vapor-Liquid-Solid Mechanism for Growing 3C-SiC Single-Domain Layers on 6H-SiC(0001), Adv. Funct. Mater. 16 (7) (2006) 975-979.

[30] Z.Y. Xie, J.H. Edgar, B.K. Burkland, J.T. George, J. Chaudhuri, DPBs-free and polytype controlled growth of $\mathrm{SiC}$ via surface etching on on-axis 6H-SiC(0001), J. Cryst. Growth 224 (2001) 235-243. 
[31] Y.A. Vodakov, A.D. Roenkov, M.G. Ramm, E.N. Mokhov, Y.N. Makarov, Use of Ta-Container for Sublimation Growth and Doping of SiC Bulk Crystals and Epitaxial Layers, Phys. Status Solidi B 202 (1997) 177-200.

[32] A.K. Geim, K.S. Novoselo, The rise of graphene, Nat. Mater. 6 (2007) 183-191.

[33] C. Lee, X.D. Wei, J.W. Kysar, H. J., Measurement of the Elastic Properties and Intrinsic Strength of Monolayer Graphene, Science 321 (2008) 385-388.

[34] P. Avouris, Graphene: electronic and photonic properties and devices, Nano Lett. 10 (11) (2010) 4285-94.

[35] A.J. Van bommel, J.E. Crinbeeb, A.V. Tooren, LEED and Auger electron observations of the SiC(0001) surface, Surf. Sci. (1975) 463-472.

[36] C. Berger, Z. Song, T. Li, X. Li, A.Y. Ogbazghi, R. Feng, Z. Dai, A.N. Marchenkov, E.H. Conrad, P.N. First, W.A. de Heer, Ultrathin Epitaxial Graphite: 2D Electron Gas Properties and a Route toward Graphene-based Nanoelectronics, J. Phys. Chem. B 108 (52) (2004) 19912-19916.

[37] K.V. Emtsev, A. Bostwick, K. Horn, J. Jobst, G.L. Kellogg, L. Ley, J.L. McChesney, T. Ohta, S.A. Reshanov, J. Rohrl, E. Rotenberg, A.K. Schmid, D. Waldmann, H.B. Weber, T. Seyller, Towards wafer-size graphene layers by atmospheric pressure graphitization of silicon carbide, Nat. Mater. 8 (3) (2009) 203-7.

[38] A. Ouerghi, M.G. Silly, M. Marangolo, C. Mathieu, M. Eddrief, M. Picher, F. Sirotti, S.E. Moussaoui, R. Belkhou, Large area and high-quality epitaxial graphene on off-axis SiC wafers, ACS Nano 6 (7) (2012) 6075-6082.

[39] N. Srivastava, G.W. He, Luxmi, P.C. Mende, R.M. Feenstra, Y.G. Sun, Graphene formed on SiC under various environments: comparison of Si-face and C-face, J. Phys. D: Appl. Phys. 45 (15) (2012) 154001.

[40] C. Virojanadara, M. Syväjarvi, R. Yakimova, L.I. Johansson, A.A. Zakharov, T. Balasubramanian, Homogeneous large-area graphene layer growth on 6H-SiC(0001), Phys. Rev. B 78 (24) (2008) 245403.

[41] G.R. Yazdi, R. Vasiliauskas, T. Iakimov, A. Zakharov, M. Syväjärvi, R. Yakimova, Growth of large area monolayer graphene on 3C-SiC and a comparison with other SiC polytypes, Carbon 57 (2013) 477-484.

[42] T. Ohta, N.C. Bartelt, S. Nie, K. Thürmer, G.L. Kellogg, Role of carbon surface diffusion on the growth of epitaxial graphene on SiC, Phys. Rev. B 81 (12) (2010) 121411(R).

[43] M. Hupalo, E.H. Conrad, M.C. Tringides, Growth mechanism for epitaxial graphene on vicinal 6HSiC(0001)surfaces: A scanning tunneling microscopy study, Phys. Rev. B 80 (4) (2009) 041401(R).

[44] C. Virojanadara, R. Yakimova, J.R. Osiecki, M. Syväjärvi, R.I.G. Uhrberg, L.I. Johansson, A.A. Zakharov, Substrate orientation: A way towards higher quality monolayer graphene growth on $6 \mathrm{H}-\mathrm{SiC}(0001)$, Surf. Sci. 603 (15) (2009) L87-L90.

[45] S. Tanaka, K. Morita, H. Hibino, Anisotropic layer-by-layer growth of graphene on vicinal SiC(0001) surfaces, Phys. Rev. B 81 (4) (2010) 041406(R).

[46] C. Vecchio, S. Sonde, C. Bongiorno, M. Rambach, R. Yakimova, V. Raineri, F. Giannazzo, Nanoscale structural characterization of epitaxial graphene grown on off-axis 4H-SiC (0001), Nanoscale Res. Lett. 6 (1)(2011) 269. 
[47] D. Pierucci, H. Sediri, M. Hajlaoui, E. Velez-Fort, Y.J. Dappe, M.G. Silly, R. Belkhou, A. Shukla, F. Sirotti, N. Gogneau, A. Ouerghi, Self-organized metal-semiconductor epitaxial graphene layer on off-axis $4 \mathrm{H}-$ SiC(0001), Nano Res. 8 (3) (2014) 1026-1037.

[48] M. Hajlaoui, H. Sediri, D. Pierucci, H. Henck, T. Phuphachong, M.G. Silly, L.A. de Vaulchier, F. Sirotti, Y. Guldner, R. Belkhou, A. Ouerghi, High Electron Mobility in Epitaxial Trilayer Graphene on Off-axis SiC(0001), Sci. Rep. (2016) 18791.

[49] T. Kajiwara, Y. Nakamori, A. Visikovskiy, T. Iimori, F. Komori, K. Nakatsuji, K. Mase, S. Tanaka, Graphene nanoribbons on vicinal SiC surfaces by molecular beam epitaxy, Phys. Rev. B 87 (12) (2013) $121407(\mathrm{R})$.

[50] R.M. Tromp, J.B. Hannon, Thermodynamics and kinetics of graphene growth on SiC(0001), Phys. Rev. Lett. 102 (10) (2009) 106104.

[51] C. Riedl, C. Coletti, U. Starke, Structural and electronic properties of epitaxial graphene on $\operatorname{SiC}\left(\begin{array}{llll}0 & 0 & 1\end{array}\right)$ : a review of growth, characterization, transfer doping and hydrogen intercalation, J. Phys. D: Appl. Phys. 43 (37) (2010) 374009 .

[52] F. Speck, J. Jobst, F. Fromm, M. Ostler, D. Waldmann, M. Hundhausen, H.B. Weber, T. Seyller, The quasifree-standing nature of graphene on H-saturated SiC(0001), Appl. Phys. Lett. 99 (12) (2011) 122106.

[53] I. Razado-Colambo, J. Avila, C. Chen, J.P. Nys, X. Wallart, M.C. Asensio, D. Vignaud, Probing the electronic properties of graphene on $\mathrm{C}$-face $\mathrm{SiC}$ down to single domains by nanoresolved photoelectron spectroscopies, Phys. Rev. B 92 (3) (2015) 035105.

[54] Y. Hu, Y. Zhang, H. Guo, L. Chong, Y. Zhang, Preparation of few-layer graphene on on-axis 4H-SiC (0001) substrates using a modified SiC-stacked method, Mater. Lett. 164 (2016) 655-658.

[55] F.S. Zhang, X.F. Chen, C.C. Yu, X.G. Xu, X.B. Hu, X. Qin, Q. Li, X. Zhao, P. Yu, R.Q. Wang, High mobility and large domain decoupled epitaxial graphene on $\mathrm{SiC}(000(1)$ over-bar) surface obtained by nearly balanced hydrogen etching, Mater. Lett. 195 (2017) 82-85.

[56] B. Sharma, T. Schumann, M.H. de Oliveira, J.M.J. Lopes, Controlled synthesis and characterization of multilayer graphene films on the C-face of silicon carbide, Phys. Status Solidi A 214 (5) (2017) 1600721.

[57] C.E. Giusca, S.J. Spencer, A.G. Shard, R. Yakimova, O. Kazakova, Exploring graphene formation on the C-terminated face of SiC by structural, chemical and electrical methods, Carbon 69 (2014) 221-229.

[58] K.V. Emtsev, F. Speck, T. Seyller, L. Ley, J.D. Riley, Interaction, growth, and ordering of epitaxial graphene on SiC $\{0001\}$ surfaces: A comparative photoelectron spectroscopy study, Phys. Rev. B 77 (15) (2008) 155303.

[59] H. Fukidome, S. Abe, R. Takahashi, K. Imaizumi, S. Inomata, H. Handa, E. Saito, Y. Enta, A. Yoshigoe, Y. Teraoka, M. Kotsugi, T. Ohkouchi, T. Kinoshita, S. Ito, M. Suemitsu, Controls over Structural and Electronic Properties of Epitaxial Graphene on Silicon Using Surface Termination of 3C-SiC(111)/Si, Appl. Phys. Exp. 4 (11) (2011) 115104.

[60] V. Darakchieva, A. Boosalis, A.A. Zakharov, T. Hofmann, M. Schubert, T.E. Tiwald, T. Iakimov, R. Vasiliauskas, R. Yakimova, Large-area microfocal spectroscopic ellipsometry mapping of thickness and 
electronic properties of epitaxial graphene on Si- and C-face of 3C-SiC(111), Appl. Phys. Lett. 102 (21) (2013) 213116.

[61] T.B. Ohta, A.; Seyller T.; Horn, K.; Rotenberg E., Controlling the Electronic Structure of Bilayer Graphene, Science 313 (5789) (2006) 951-4.

[62] K.S. Novoselov, E. McCann, S.V. Morozov, V.I. Fal'ko, M.I. Katsnelson, U. Zeitler, D. Jiang, F. Schedin, A.K. Geim, Unconventional quantum Hall effect and Berry's phase of $2 \pi$ in bilayer graphene, Nat. Phys. 2 (3) (2006) 177-180.

[63] A. Yacoby, Tri and tri again, Nat. Phys. 7 (12) (2011) 925-926.

[64] C.H. Lui, Z.Q. Li, K.F. Mak, E. Cappelluti, T.F. Heinz, Observation of an electrically tunable band gap in trilayer graphene, Nat. Phys. 7 (12) (2011) 944-947.

[65] Y.P. Liu, S. Goolaup, W.S. Lew, I. Purnama, M. Chandra Sekhar, T.J. Zhou, S.K. Wong, Excitonic bandgap dependence on stacking configuration in four layer graphene, Appl. Phys. Lett. 103 (16) (2013) 163108

[66] D. Pierucci, T. Brumme, J.C. Girard, M. Calandra, M.G. Silly, F. Sirotti, A. Barbier, F. Mauri, A. Ouerghi, Atomic and electronic structure of trilayer graphene/SiC(0001): Evidence of Strong Dependence on Stacking Sequence and charge transfer, Sci. Rep. 6 (2016) 33487.

[67] D. Pierucci, H. Sediri, M. Hajlaoui, J.C. Girard, T. Brumme, M. Calandra, E. Velez-Fort, G. Patriarche, M.G. Silly, G. Ferro, V. Souliere, M. Marangolo, F. Sirotti, F. Mauri, A. Ouerghi, Evidence for Flat Bands near the Fermi Level in Epitaxial Rhombohedral Multilayer Graphene, ACS Nano 9 (5) (2015) 5432-5439.

[68] L. Zhang, Y. Zhang, J. Camacho, M. Khodas, I. Zaliznyak, The experimental observation of quantum Hall effect of $1=3$ chiral quasiparticles in trilayer graphene, Nat. Phys. 7(12) (2011) 953-957.

[69] W. Bao, L. Jing, J. Velasco, Y. Lee, G. Liu, D. Tran, B. Standley, M. Aykol, S.B. Cronin, D. Smirnov, M.Koshino, E. McCann, M. Bockrath, C.N. Lau, Stacking-dependent band gap and quantum transport in trilayer graphene, Nat. Phys. 7 (12) (2011) 948-952.

[70] J. Hass, F. Varchon, J.E. Millan-Otoya, M. Sprinkle, N. Sharma, W.A. de Heer, C. Berger, P.N. First, L. Magaud, E.H. Conrad, Why multilayer graphene on $4 \mathrm{H}-\mathrm{SiC}(000-1)$ behaves like a single sheet of graphene, Phys. Rev. Lett. 100 (12) (2008) 125504.

[71] J. Hass, R. Feng, J.E. Millán-Otoya, X. Li, M. Sprinkle, P.N. First, W.A. de Heer, E.H. Conrad, C. Berger, Structural properties of the multilayer graphene $/ 4 \mathrm{H}-\mathrm{SiC}\left(0001^{-}\right)$system as determined by surface $\mathrm{x}$-ray diffraction, Phys. Rev. B 75 (21) (2007) 214109.

[72] C. Berger, Z.M. Song, X.B. Li, X.S. Wu, N. Brown, C. Naud, D. Mayou, T.B. Li, J. Hass, A.N. Marchenkov, E.H. Conrad, P.N. First, d.H.W. A., Electronic Confinement and Coherence in Patterned Epitaxial Graphene, Science 312 (2006) 1191-1195.

[73] Y.M. Lin, C. Dimitrakopoulos, D.B. Farmer, S.J. Han, Y.Q. Wu, W.J. Zhu, D.K. Gaskill, J.L. Tedesco, R.L. Myers-Ward, C.R. Eddy, A. Grill, P. Avouris, Multicarrier transport in epitaxial multilayer graphene, Appl. Phys. Lett. 97 (11) (2010) 112107.

[74] M. Sprinkle, M. Ruan, Y. Hu, J. Hankinson, M. Rubio-Roy, B. Zhang, X. Wu, C. Berger, W.A. de Heer, Scalable templated growth of graphene nanoribbons on SiC, Nat. Nanotechnol. 5 (10) (2010) 727-731.

[75] Y.W. Son, M.L. Cohen, S.G. Louie, Half-metallic graphene nanoribbons, Nature 444 (7117) (2006) 347-9. 
[76] X. Liang, Y.-S. Jung, S. Wu, A. Ismach, D.L. Olynick, S. Cabrini, J. Bokor, Formation of Bandgap and Subbands in Graphene Nanomeshes with Sub-10 nm Ribbon Width Fabricated via Nanoimprint Lithography, Nano Lett. 10 (7) (2010) 2454-2460.

[77] L. Brey, H.A. Fertig, Electronic states of graphene nanoribbons studied with the Dirac equation, Phys. Rev. B 73 (23) (2006) 235411.

[78] G.Z. Magda, X. Jin, I. Hagymási, P. Vancsó, Z. Osváth, P. Nemes-Incze, C. Hwang, L.P. Biró, L. Tapasztó, Room-temperature magnetic order on zigzag edges of narrow graphene nanoribbons, Nature 514 (7524) (2014) 608-611.

[79] Y.W. Son, M.L. Cohen, S.G. Louie, Energy Gaps in Graphene Nanoribbons, Phys. Rev. Lett. 97 (21) (2006) 216803.

[80] M.Y. Han, J.C. Brant, P. Kim, Electron Transport in Disordered Graphene Nanoribbons, Phys. Rev. Lett. 104 (5) (2010) 056801.

[81] J. Cai, P. Ruffieux, R. Jaafar, M. Bieri, T. Braun, S. Blankenburg, M. Muoth, A.P. Seitsonen, M. Saleh, X.Feng, K. Mullen, R. Fasel, Atomically precise bottom-up fabrication of graphene nanoribbons, Nature 466 (7305) (2010) 470-3.

[82] L. Jiao, L. Zhang, X. Wang, G. Diankov, H. Dai, Narrow graphene nanoribbons from carbon nanotubes, Nature 458 (7240) (2009) 877-80.

[83] L. Tapasztó, G. Dobrik, P. Lambin, L.P. Biró, Tailoring the atomic structure of graphene nanoribbons by scanning tunneling microscope lithography, Nat. Nanotechnol. 3 (7) (2008) 397-401.

[84] A. Stöhr, J. Baringhaus, J. Aprojanz, S. Link, C. Tegenkamp, Y. Niu, A.A. Zakharov, C. Chen, J. Avila, M.C. Asensio, U. Starke, Graphene Ribbon Growth on Structured Silicon Carbide, Ann. Phys. 529 (11) (2017) 1700052 .

[85] X. Li, X. Wang, L. Zhang, S. Lee, H. Dai, Chemically derived, ultrasmooth graphene nanoribbon semiconductors, Science 319 (5867) (2008) 1229-32.

[86] T. Kimoto, A. Itoh, H. Matsunami, T. Okano, Step bunching mechanism in chemical vapor deposition of 6H- and 4H-SiC $\{0001\}$, J. Appl. Phys. 81 (8) (1997) 3494.

[87] G. Nicotra, Q.M. Ramasse, I. Deretzis, A. La Magna, C. Spinella, F. Giannazzo, Delaminated graphene at silicon carbide facets: atomic scale imaging and spectroscopy, ACS Nano 7 (4) (2013) 3045-52.

[88] J. Baringhaus, M. Ruan, F. Edler, A. Tejeda, M. Sicot, A. Taleb-Ibrahimi, A.P. Li, Z.G. Jiang, E.H. Conrad, C. Berger, C. Tegenkamp, W.A. de Heer, Exceptional ballistic transport in epitaxial graphene nanoribbons, Nature 506 (7488) (2014) 349-54.

[89] A.L. Miettinen, M.S. Nevius, W. Ko, M. Kolmer, A.-P. Li, M.N. Nair, B. Kierren, L. Moreau, E.H. Conrad, A. Tejed, Edge states and ballistic transport in zig-zag graphene ribbons_the role of SiC polytypes, condmat.mes-hall arXiv:1903.05185 (2019).

[90] R. Krol, M. Grätzel, Photoelectrochemical Hydrogen Production, Electron. Mater.: Sci. \& Technol. ISBN 978-1-4614-1379-0, 13-58 (2012).

[91] R. van de Krol, Y. Liang, J. Schoonman, Solar hydrogen production with nanostructured metal oxides, J. Mater. Chem. 18 (20) (2008) 2311-2320. 
[92] M.F. WEBER, M.J. DIGNAM, Splitting water with semiconducting photoelectrodes-efficiency considerations, Int. J. Hydrog. Energy 11 (4) (1986) 225-232.

[93] A. Murphy, P. Barnes, L. Randeniya, I. Plumb, I. Grey, M. Horne, J. Glasscock, Efficiency of solar water splitting using semiconductor electrodes, Int. J. Hydrog. Energy 31 (14) (2006) 1999-2017.

[94] M. Grätzel, Photoelectrochemical cells, Nature 414 (15) (2001) 338-344.

[95] M. Kato, T. Yasuda, K. Miyake, M. Ichimura, T. Hatayama, Epitaxial p-type SiC as a self-driven photocathode for water splitting, Int. J. Hydrog. Energy 39 (10) (2014) 4845-4849.

[96] H. Hibino, H. Kageshima, F. Maeda, M. Nagase, Y. Kobayashi, H. Yamaguchi, Microscopic thickness determination of thin graphite films formed on $\mathrm{SiC}$ from quantized oscillation in reflectivity of low-energy electrons, Phys. Rev. B 77 (7) (2008) 075413.

[97] S. Nakashima, H. Harima, Raman Investigation of SiC Polytypes, Phys. Status Solidi A 162 (39) (1997) 39-64.

[98] Y. Shi, V. Jokubavicius, P. Höjer, I.G. Ivanov, G.R. Yazdi, R. Yakimova, M. Syväjärvi, J.W. Sun, A comparative study of high-quality $\mathrm{C}$-face and Si-face 3C-SiC(1 111$)$ grown on off-oriented 4H-SiC substrates, J. Phys. D: Appl. Phys. 52 (34) (2019) 345103.

[99] A.C. Ferrari, J.C. Meyer, V. Scardaci, C. Casiraghi, M. Lazzeri, F. Mauri, S. Piscanec, D. Jiang, K.S. Novoselov, S. Roth, A.K. Geim, Raman spectrum of graphene and graphene layers, Phys. Rev. Lett. 97 (18) (2006) 187401.

[100] L.M. Malard, M.A. Pimenta, G. Dresselhaus, M.S. Dresselhaus, Raman spectroscopy in graphene, Phys. Rep. 473 (5-6) (2009) 51-87.

[101] A. Das, S. Pisana, B. Chakraborty, S. Piscanec, S.K. Saha, U.V. Waghmare, K.S. Novoselov, H.R. Krishnamurthy, A.K. Geim, A.C. Ferrari, A.K. Sood, Monitoring dopants by Raman scattering in an electrochemically top-gated graphene transistor, Nat. Nanotechnol. 3 (4) (2008) 210-5.

[102] D. Graf, F. Molitor, K. Ensslin, C. Stampfer, A. Jungen, C. Hierold, L. Wirtz, Spatially Resolved Raman Spectroscopy of Single and Few-Layer Graphene, Nano Lett. 7 (2) (2007) 238-242.

[103] A.C. Ferrari, Raman spectroscopy of graphene and graphite: Disorder, electron-phonon coupling, doping and nonadiabatic effects, Solid State Commun. 143 (1-2) (2007) 47-57.

[104] I.G. Ivanov, J.U. Hassan, T. Iakimov, A.A. Zakharov, R. Yakimova, E. Janzén, Layer-number determinat ion in graphene on SiC by reflectance mapping, Carbon 77 (2014) 492-500. 


\section{Papers}

The papers associated with this thesis have been removed for copyright reasons. For more details about these see:

http://urn.kb.se/resolve?urn=urn:nbn:se:liu:diva-159100 


\section{FACULTY OF SCIENCE AND ENGINEERING}

Linköping Studies in Science and Technology, Dissertation No. 2003, 2019 Department of Physics, Chemistry and Biology (IFM)

Linköping University

SE-581 83 Linköping, Sweden

www.liu.se 